\title{
Coordinación Salarial Gubernamental e Inter-Sectorial en el Neo-Corporativismo Segmentado: Orígenes y Desempeño en Argentina y Uruguay (2005-2015)*
}

Inter-Sectoral and Government Wage Coordination in Segmented

Neo-Corporatism: Origins and Performance in Argentina and Uruguay (2005-2015).

\section{SEBASTIÁN ETCHEMENDY}

Departamento de Ciencia Política y Estudios Internacionales,

Universidad Torcuato Di Tella, Argentina

setchemendy@utdt.edu

El neo-corporativismo como forma de política de ingresos está en retirada en el mundo desarrollado y no fue parte del repertorio de la mayoría de los países que protagonizaron el giro a la izquierda en la América Latina de los años 2000. Este artículo muestra, sin embargo, que Argentina y Uruguay constituyeron casos de «Neo-corporativismo Segmentado» a partir de 2005, definido como una nueva forma de política salarial centralizada y tripartita orientada por el Estado en la región, que aplica a una porción sustancial (trabajadores registrados), aunque no a toda la fuerza de trabajo asalariada. El artículo rastrea los orígenes de esta forma de política de intereses en ambos países y testea empiricamente el grado de coordinación salarial en dos dimensiones a) dispersión intersectorial entre sindicatos que operan en actividades transables, protegidas y en el sector público, y b) la capacidad de los gobiernos para elaborar pautas salariales efectivas. El trabajo argumenta que una política monetaria más restrictiva y los altos niveles de centralización en la negociación tripartita explican la mayor capacidad del neo-corporativismo uruguayo para gobernar la politica salarial en comparación a la contraparte argentina.

\section{Introducción}

La expansión de políticas de ingreso neo-corporativas en Argentina y Uruguay desde mediados de los años 2000, es decir la negociación salarial centralizada entre sindicatos y empresarios orientada por un Estado democrático, es notable por varias razones, tanto a escala regional como mundial.

* $\quad$ El autor agradece los aportes de dos evaluadores anónimos de Revista SAAP, a una versión previa de este artículo. 
Dentro del llamado «Giro a la Izquierda en América Latina» que comenzó a principios de esa década, solo Argentina y Uruguay conformaron una alianza gubernamental de base sindical, donde trabajadores organizados y empresarios discuten salarios sectoriales a nivel país con coordinación estatal, y establecen un salario mínimo nacional para el sector privado en forma tripartita. Solo el Brasil de Lula fue testigo de una alianza gobierno-sindicatos comparable, pero sin los elementos de concertación salarial nacional y empoderamiento gremial en el mercado de trabajo presentes en los casos argentino y uruguayo (Schipani, 2018).

En términos globales, la expansión del neo-corporativismo en esta parte del Cono Sur también es remarcable. El corporativismo democrático tuvo su apogeo en la década de 1970 y principios de la década de 1980 en Europa, cuando sindicatos, empresarios y gobiernos convergieron en negociaciones salariales centralizadas que produjeron mejores resultados que los modelos más descentralizados en términos de estabilidad macroeconómica y gobernabilidad (Schmitter, 1981; Cameron, 1984). A partir de entonces, tendencias económicas estructurales, políticas e internacionales entrelazadas socavaron los cimientos de la negociación salarial de nivel nacional y agregado. De hecho, la mayor parte de la literatura sobre economía política comparada, al menos desde fines de la década del 90, advierte sobre la desaparición o descentralización de la negociación neo-corporativa en el mundo desarrollado. La coordinación salarial sigue siendo, por supuesto, una característica central de algunas Economías de Mercado Coordinadas (EMC) de países de Europa continental y nórdica. Sin embargo, en la mayoría de los casos está restringida a un juego inter-sectorial con menor intervención del gobierno que hace 30 años (Hall y Soskice, 2001, Baccaro y Regini, 2011) ${ }^{1}$.

Así, mientras las bases económicas y políticas del neo-corporativismo se derretían en gran parte de Europa Occidental, las características asociadas con el concepto-coordinación salarial centralizada orientada por el Estado e intercambio político entre un gobierno de partido con base sindical y un movimiento obrero relativamente unificado-se convirtieron en un paisaje común en esta periferia latinoamericana. Comenzando en 2004-2005 el Frente Amplio (FA) en Uruguay y los gobiernos peronistas de los Kirchner en Argentina lanzaron y trataron de coordinar diversas rondas de negociación salarial de actividad/sector complementadas por la concertación nacional tripartita de un ingreso mínimo para el sector privado. En ambos casos, además, estas formas neo-corporativas fueron complementadas con la creación de consejos de salario para trabajadores tradicionalmente excluidos de la negociación de nivel nacional, como rurales, docentes y de casas particu-

La bibliografía sobre neo corporativismo es por supuesto enorme. Tal vez el análisis más completo de la trayectoria del concepto es Streeck (2006). 


\section{Sebastián Etchemendy}

lares. En otras palabras, los salarios en Argentina y Uruguay han sido, desde mediados de los 2000, en gran parte moldeados por la política y no simplemente por las fuerzas del mercado

Significativamente, las formas de la coordinación salarial centralizada que emergieron en Argentina y Uruguay en los 2000 se asimilan más al neocorporativismo europeo de la post guerra que a los históricos arreglos corporativistas en América Latina: los gobiernos de base popular convergieron con movimientos sindicales hegemónicos bajo regímenes democráticos en donde los gremios son autónomos y no controlados desde arriba. Sin embargo, para diferenciar este patrón sudamericano contemporáneo de la experiencia europea, siguiendo a Etchemendy y Collier (2007), defino al neo-corporativismo segmentado como un modo de negociación a nivel de cúpulas en donde los sindicatos monopólicos, las asociaciones empresariales y los gobiernos tratan de coordinar acuerdos salariales de actividad y pisos de salarios mínimos nacionales, que aplican a una porción sustancial, pero no a toda, la fuerza de trabajo. Dada la naturaleza fragmentada del mercado de trabajo en ambos países, este modo de negociación salarial excluye entre un cuarto y un tercio de los trabajadores asalariados.

Este artículo tiene dos objetivos principales. El primero es explicar por qué Argentina y Uruguay fueron los únicos dos países en la región (incluso en el contexto del resurgimiento de la izquierda en los 2000) en desarrollar coordinación salarial neo-corporativa después del neoliberalismo. Segundo, intenta medir y explicar el grado de coordinación salarial en ambos países, y la habilidad de los partidos populares para gobernar la fijación de los salarios en un contexto de una ofensiva sindical y economías liberalizadas en los años 90. El estudio tiene dos hipótesis principales:

Hipótesis 1: Argentina y Uruguay comparten dos características institucionales esenciales, ausentes en el resto de América Latina, y decisivas para la emergencia del neo corporativismo. Primero, ambos gobiernos contaban con un marco institucional para negociar acuerdos colectivos nacionales y sectoriales originalmente establecido en los años 40, que había sido congelado, pero nunca derogado, por el neoliberalismo ya sea autoritario o democrático. Segundo, ambos países desarrollaron movimientos sindicales de alcance nacional relativamente unificados, afiliados a los partidos del sector popular que encabezaron el giro a la izquierda.

En ambos países la existencia de un marco institucional «congelado» pero legal y potencialmente obligatorio para organizar las paritarias de actividad y el salario mínimo nacional, facilitaron el rápido lanzamiento de la 
negociación salarial centralizada por decreto. Además, los partidos de base popular como el PJ y el FA, construyeron una asociación histórica con un movimiento sindical que había alcanzado el monopolio de la representación en la mayoría de los sectores de la economía. Principios básicos de la teoría neo-corporativista proponen que el monopolio sindical resuelve problemas de acción colectiva y facilita la centralización de las negociaciones. En resumen, legados institucionales previos al giro a la izquierda en Argentina y Uruguay, no presentes en el resto de la región, hicieron posible la emergencia de políticas de ingresos tripartita y centralizadas.

Hipótesis 2: En Uruguay, la combinación de un régimen de política monetaria mínimamente creíble de metas de inflación y una mayor centralización de las negociaciones salariales, permitieron una mayor coordinación de las políticas de ingresos tripartitas que en Argentina.

La coordinación salarial puede ser medida de dos maneras principales: a) la divergencia intersectorial en el desempeño salarial y b) el grado en que los gobiernos logran mantener incremento salarial dentro de sus necesidades macroeconómicas y los parámetros de crecimiento que elabora en cada ronda. En ambos países, la concertación salarial neo-corporativa ha sido en gran medida (y quizás sorprendentemente) exitosa para hacer frente a la dispersión salarial entre trabajadores estatales y del sector privado, y en menor medida (especialmente en el caso uruguayo) entre sindicatos en sectores transables y no transables. La baja dispersión entre ingresos de trabajadores privados y estatales, y aquellos en sectores más o menos expuestos al comercio exterior, son condiciones básicas para el buen funcionamiento de la coordinación salarial según la teoría neo-corporativista (ver discusión abajo).

Sin embargo, en este trabajo muestro que, en contraste con Argentina, en Uruguay el crecimiento salarial se ha mantenido a grandes rasgos dentro de los parámetros y lineamientos generales del gobierno. En el neo-corporativismo, la capacidad de los partidos con base sindical para gobernar la fijación del salario de acuerdo con sus objetivos macroeconómicos es crucial. Primero, una política monetaria más restrictiva y de tasas positivas en Uruguay (esto es, una que, a diferencia de Argentina, estuvo sujeta a metas de inflación por la autoridad monetaria) moldeó las expectativas económicas de los actores. En otras palabras, proyecciones mínimamente creíbles de inflación contuvieron las presiones salariales (en línea con las predicciones de la literatura neo corporativista de finales de los años 90, ver abajo), especialmente a partir del fin del ciclo de crecimiento económico post 2012 . Segundo, mayores niveles de centralización en la negociación reforzaron la 


\section{Sebastián Etchemendy}

coordinación en Uruguay: el gobierno presenta un lineamiento salarial formal, en un ámbito institucional tripartito de cobertura nacional, a una confederación sindical claramente unificada. En Argentina parámetros salariales informales por parte del gobierno, la ausencia de un nivel nacional (esto es, inter-sectorial) de discusión en un consejo de concertación salarial, y las divisiones dentro del movimiento obrero a nivel confederado, socavaron la coordinación gubernamental. Los menores grados de coordinación salarial en Argentina contribuyeron a la inestabilidad macroeconómica especialmente entre 2012 y 2015.

Este estudio emplea el método comparado para testear sus principales hipótesis. La literatura neo-corporativista tiene, por supuesto, una rica tradición cualitativa y cuantitativa. Sin embargo, en la América Latina moderna, los análisis large- $n$ cuantitativos de política de ingresos neo-corporativa están restringidos, en primer lugar, por el pequeño número de casos que extendieron una negociación económica nacional (sólo dos países, Argentina y Uruguay). Sumando a esto, todavía no tenemos en Latinoamérica datos comparables sobre la densidad sindical, negociación centralizada, participación de las confederaciones nacionales y dispersión salarial, del tipo que utilizan los tradicionales análisis de large-n en el neo-corporativismo de Europa Occidental. Por lo tanto, construí una Base de Datos de Convenios Colectivos con el nivel de salarios nominales de 23 sindicatos que están entre los que abarcan más trabajadores de cada país entre 2005 y 2015. En Argentina, el Ministerio de Trabajo, Empleo y Seguridad Social compila los niveles de salario nominal de 21 contratos de sindicatos privados, más los maestros y los empleados de la administración central en el sector público. En Uruguay, reuní datos de estos mismos convenios, que también tienden a estar entre los más grandes. En general, los convenios sectoriales seleccionados representan alrededor del $70 \%$ del total de los trabajadores registrados en Argentina y $80 \%$ en Uruguay ${ }^{2}$.

La hipótesis 1 está analizada en términos de la estrategia de los casos más diferentes (Skopcol y Sommers, 1986; Gerring, 2001, p. 212). El argumento explora las instituciones comunes que, a pesar de las diferencias históricas marcadas en el desarrollo político de Argentina y Uruguay, favorecieron el manejo salarial neo-corporativo después de 2005. El artículo sigue criterios metodológicos estándar en el sentido de que la estrategia de los casos más diferentes (a pesar de su obvia desventaja en cuanto a la no variación de la variable dependiente) puede ayudar a evaluar potenciales condiciones necesarias para este tipo periférico de neo-corporativismo, especialmente en los casos polares o «extremos» como Argentina y Uruguay (Mahoney, 2007, p. 129; Gerring, 2001, p.214).

2 Para más detalles de la construcción de la base de datos ver Apéndice. 
La hipótesis 2 está enmarcada en el método comparado de los casos más similares: en un contexto general común de negociación salarial neocorporativa, este estudio investiga las condiciones que posibilitaron una política de ingresos más o menos coordinada. La primera parte del artículo revisa el pasado y el presente de la teoría neo-corporativista y sus prácticas actuales en América del Sur y Europa. La segunda parte ofrece una explicación del surgimiento inesperado de la coordinación salarial centralizada en Argentina y Uruguay. La tercera y cuarta parte analizan en mayor profundidad el desempeño del neo-corporativismo, concentrándose en los grados de divergencia inter-sectoriales y en la capacidad de los partidos populares de gobernar la fijación de los salarios.

\section{2. (Neo) Corporativismo y el Cono Sur latinoamericano: Teoría y Práctica}

\section{a) La evolución del concepto: América Latina y Europa}

Las experiencias de Argentina y Uruguay en políticas de ingreso neocorporativas durante el giro a la izquierda en los años 2000 son una novedad en la historia de América Latina. El corporativismo en su versión estatista fue, por supuesto, un dispositivo institucional central que artículo históricamente la inclusión política de los nuevos sectores populares urbanos y rurales en Latinoamérica desde los años $30 \mathrm{del}$ s. $\mathrm{XX}^{3}$. Las estrategias de corporativismo estatal, tales como el reconocimiento estatal legal, o el empoderamiento y monitoreo de sindicatos, permitieron la incorporación subordinada de vastas porciones del movimiento obrero a un nuevo proyecto político «modernizador». El balance de incentivos y restricciones estatales que dieron forma al movimiento obrero emergente, y por lo tanto el poder y el grado de autonomía de los sindicatos en América Latina, varió de caso en caso (Collier y Collier, 1979). No obstante, los acuerdos salariales sostenidos entre actores socioeconómicos relativamente autónomos fueron raros en América Latina, mayormente porque el autoritarismo y la subordinación sindical impidieron cualquier tipo de negociación significativa.

Se podía pensar que la democratización y fortalecimiento sindical posterior a las dictaduras, sumados al resurgimiento de los partidos de izquierda y nacional populares en los años 2000, sembraban las bases para una ola de empoderamiento gremial y políticas de ingreso inclusivas en América Latina. Sin embargo, el giro a la izquierda no ha sido demasiado grato para

Collier y Collier (1991). Para diversos usos del concepto en el contexto latinoamericano ver el trabajo seminal en Malloy (1977) y Collier (1993). 


\section{Sebastián Etchemendy}

los sindicatos en la región. En casos como los de Ecuador, Venezuela y Bolivia los gobiernos de izquierda buscaron el apoyo fundamentalmente en los sectores populares informales. En los primeros dos casos confrontaron abiertamente con los sindicatos establecidos (Etchemendy, 2019, Silva y Rossi, 2018). Algunos autores postularon la posibilidad de un camino "socialdemócrata» en el Cono Sur, donde la mayor tradición sindical podía retomar el eco de las tradicionales alianzas entre partidos progresistas y movimiento obrero, comunes en la Europa de posguerra. Sin embargo, en el Brasil de Lula, en el marco de una política económica claramente ortodoxa, el gobierno eludió el camino del empoderamiento sindical en el mercado de trabajo (Schipani, 2018). En Chile, la exclusión de sindicatos y movimientos sociales en los gobiernos progresistas de la Concertación 1990-2010 fue aún mayor (Roberts, 2016).

En suma, el paraguas conceptual para entender los procesos de política de ingreso centralizada en los contextos democráticos post-neoliberales en el Cono Sur, debemos buscarlo más en los casos históricos de corporativismo democrático europeo que en el pasado de corporativismo estatal y escasa autonomía de los actores económicos, o en un presente donde predomina la exclusión sindical en América Latina. Así, este trabajo considera el concepto neo-corporativismo en sus dos significados generales acuñados en la Edad de Oro de los 70‘s y 80‘s, uno más estructural/organizacional y otro más relacionado a la formulación de políticas. Primero, es un modo de política de intereses signado por el monopolio en la representación de los actores económicos (especialmente trabajadores) reconocido por el Estado. Segundo, involucra altos niveles de concertación, especialmente de políticas de ingresos, entre el Estado, los empleadores y los sindicatos. Estas dos dimensiones del neo-corporativismo, en el ámbito de la representación de intereses y de la política pública, están enfatizados por los precursores que también se refirieron al concepto, con diferencias mínimas, como «corporativismo societal» (Schmitter, 1981), «liberal» (Lehmbruch, 1977) y «democrático» (Katzenstein, 1985).

En Europa, las negociaciones salariales de cúpula probaron ser una herramienta eficiente para moderar las demandas salariales, proteger el empleo y controlar la inflación en los 70‘s y 80‘s (Schmitter, 1981; Cameron, 1984; Calmfors y Driffill, 1988). Posteriormente, el incremento en la movilidad de capitales y la integración económica y cambiaria desafiaron de manera decisiva el pacto neo-corporativista. Las dificultades de los gobiernos nacionales para controlar las tasas de interés y la amenaza de fuga de capitales socavaron los pactos salariales y los parámetros de inflación (Scharpf, 1991) asociados a ellos. Además, el monetarismo y la teoría de las expectativas racionales en macroeconomía pusieron en duda los efectos reales de largo plazo de las políticas monetarias y fiscales, desafiando los fundamen- 
tos keynesianos de la teoría neo-corporativista. Sin embargo, entre mediados y finales de los 90' un grupo de académicos integró la economía postKeynesiana y el neo-corporativismo. Subrayaron que incluso en un mundo de movilidad de capitales, políticas monetarias restrictivas y bancos centrales independientes, las instituciones laborales aún importaban. La política macroeconómica podía tener efectos reales: la negociación centralizada con inclusión del movimiento sindical, apropiadamente combinada con bancos centrales independientes y más autónomos en el manejo de la política monetaria, aún producían mejores resultados en términos de inflación y desempleo (Hall, 1994; Iversen, 1999; Soskice and Iversen, 2000; Franzese y Hall, 2000; Iversen y Pontusson, 2000).

Sin embargo, justo cuando esta «segunda ola» de estudios neo-corporativistas subrayó la importancia de los juegos estratégicos entre los gobiernos, movimientos sindicales centralizados y autoridades monetarias nacionales, la consolidación del Banco Central Europeo (BCE) y el Euro en los 2000 reformularon otra vez las condiciones para el intercambio político neocorporativo. Los gobiernos perdían el control de la política monetaria y el tipo de cambio, - parámetros fundamentales para orientar la política de ingresos en el ciclo anterior-, y las relaciones industriales tendieron a una mayor desregulación (Baccaro y Howell, 2011). La negociación salarial centralizada en los países de economía de mercado coordinadas, se restringe entonces a un juego inter-sectorial, donde los sectores más competitivos marcan el ritmo con pocos insumos del gobierno (Hall y Soskice, 2001).

\section{b) Neo-Corporativismo Segmentado y Giro a la Izquierda en América Latina: Argentina y Uruguay}

Tanto en Argentina como en Brasil, gobiernos apoyados por los sindicatos pusieron en marcha rápidamente mecanismos para la coordinación salarial centralizada. En Argentina, Kirchner nombró a Carlos Tomada, un conocido abogado peronista vinculado al movimiento sindical, como Ministro de Trabajo. Con el fin de contrarrestar la baja de ingresos causada por la violenta devaluación de 2002, durante los años 2003 y 2004 el gobierno decretó unilateralmente una serie de aumentos salariales. Para 2004, sin embargo, el gobierno ordenó que cada aumento salarial decretado debía ser incluido en convenios colectivos de cada la actividad económica negociados por sindicatos y empleadores, lanzando, de este modo, la rueda de las negociaciones sectoriales (Etchemendy y Collier, 2007). En 2004 el gobierno también estableció por decreto el Consejo de Salario Mínimo Nacional tripartito, que después de las deliberaciones entre los actores sociales estableció 


\section{Sebastián Etchemendy}

un salario mínimo para el sector privado y para la administración pública nacional por primera vez en 11 años.

En Uruguay, la victoria del Frente Amplio (FA) en 2005 culminó décadas de paciente construcción política por parte de la izquierda (Buquet y Chasquetti, 2005; Luna, 2007). El Frente Amplio, una coalición formada por comunistas, socialistas, movimientos nacional-populares e incluso grupos que rompieron con los partidos tradicionales Colorado y Blanco, se jactó del apoyo del movimiento obrero desde sus orígenes, en 1970. Tan solo días después de asumir el cargo, Tabaré Vázquez, el presidente socialista, emitió un decreto llamando a la reinstalación de los Consejos de Salarios sectoriales, que habían sido suspendidos en los años 90 y durante la reciente crisis económica. La reconstrucción de los Consejos de Salario, formados por representantes del Estado, empleadores y sindicatos, era una demanda prominente de PIT-CNT (Confederación Nacional de Trabajadores-Plenario Intersindical de Trabajadores), aliada al Frente Amplio.

Por lo tanto, más o menos al mismo tiempo (2005), los salarios en Argentina y Uruguay comenzaron a ser establecidos en instancias sectoriales/ nacionales de negociaciones centralizadas. Estas negociaciones salariales son sectoriales en el sentido de que son válidas para todos los trabajadores en una actividad económica general. Pero también nacionales en el sentido de que a) cubren todo el sector de actividad a nivel nacional, y no simplemente algunas regiones o provincias, y b) están enmarcadas, como analizaremos a continuación, por acuerdos generales de políticas de ingreso más o menos formales. Ambos países también lanzaron nuevos consejos salariales para establecer el salario mínimo de trabajadores urbanos privados, y también para maestros, trabajadores domésticos y rurales a escala nacional. La Tabla 1 provee una mirada a los niveles contemporáneos (2015) de fijación de salarios y poder sindical en Argentina y Uruguay, comparados con una selección de países latinoamericanos que cuentan con una tradición de activismo sindical mínima. Las economías políticas neo-corporativas de Argentina (hasta 2015) y Uruguay, son por lejos las que cuentan con patrones más centralizados de negociación: los salarios del sector privado se negocian por sector, y todos los colectivos de trabajadores registrados tienen un consejo nacional de fijación de salarios. Además, en lo que respecta a la fuerza sindical nacional, ambos países simplemente practican un juego diferente que en el resto del continente: la densidad (afiliación) sindical duplica la tasa de países que tienen, o que tuvieron alguna vez, movimientos sindicales activos, tales como Brasil o Chile. Aunque no tenemos datos comparativos confiables, la cobertura de la negociación colectiva tanto en Argentina como en Uruguay, debido a las reglas de extensión, alcanzan a casi todos los trabajadores formales (ya sean sindicalizados o no), y es por lejos más grande que en el resto de América Latina. 


\section{TABLA 1}

Niveles de Negociación Salarial para Segmentos Alternativos de la Clase Trabajadora y Densidad Sindical. Países seleccionados de América Latina 2005-2015

\begin{tabular}{|c|c|c|c|c|c|c|c|}
\hline & $\begin{array}{c}\text { Principal } \\
\text { Nivel de } \\
\text { Negociación } \\
\text { Sector } \\
\text { Privado }\end{array}$ & $\begin{array}{c}\text { Consejo de } \\
\text { Salario Mínimo } \\
\text { Nacional } \\
\text { (Sector Urbano } \\
\text { Privado) }\end{array}$ & $\begin{array}{c}\text { Consejo de } \\
\text { Salario } \\
\text { Nacional } \\
\text { (Rural) }\end{array}$ & $\begin{array}{c}\text { Consejo de } \\
\text { Salario } \\
\text { Nacional } \\
\text { (Trabajadores } \\
\text { del Estado) }\end{array}$ & $\begin{array}{c}\text { Consejo de } \\
\text { Salario } \\
\text { Nacional } \\
\text { (Maestros) }\end{array}$ & $\begin{array}{c}\text { Consejo de } \\
\text { Salario } \\
\text { Nacional } \\
\text { (Trabajadores } \\
\text { Domésticos) }\end{array}$ & $\begin{array}{c}\text { Tasa de } \\
\text { densidad } \\
\text { sindical (\%) }\end{array}$ \\
\hline $\begin{array}{c}\text {-Nacional } \\
- \text {-Sector/ } \\
\text { Actividad }\end{array}$ & $\mathrm{Si}$ & $\mathrm{Si}$ & $\mathrm{Si}$ & $\mathrm{Si}$ & $\mathrm{Si}$ & $30,1^{\mathrm{a}}$ \\
\hline Argentina & $\begin{array}{c}- \text { Sector/ } \\
\text { Actividad }\end{array}$ & $\mathrm{Si}$ & $\mathrm{Si}$ & $\mathrm{Si}$ & $\mathrm{Si}$ & $\mathrm{Si}$ & $37,7^{\mathrm{b}}$ \\
\hline Brazil & - -Municipal & $\mathrm{No}$ & $\mathrm{No}$ & $\mathrm{Si}$ & $\mathrm{No}$ & No & $16,6^{\mathrm{c}}$ \\
\hline México & Firma & $\mathrm{Si}$ & $\mathrm{No}$ & $\mathrm{No}$ & $\mathrm{Si}$ & No & $13,6^{\mathrm{d}}$ \\
\hline Peru & Firma & $\mathrm{Si}$ & No & No & No & No & $4,2^{\mathrm{e}}$ \\
\hline Chile & Firma & $\mathrm{No}$ & No & No & No & No & $15^{\mathrm{f}}$ \\
\hline
\end{tabular}

Fuente: Elaboración del Autor basado en análisis por país. Como se explica abajo, Uruguay combina niveles de negociación nacionales/confederal con los Consejos Salariales Sectoriales. La densidad sindical es de OIT, http://www.ilo.org/ilostat/faces/ oracle/webcenter/portalapp/pagehierarchy/Page3.jspx?MBI_ID =9

*a) 2013, b)2008, c) 2013 d) 2013 e) 2012 f) 2013.

En ambos países los trabajadores en condiciones de informalidad disminuyeron sustancialmente después de 2005: para 2015 24.9\% de los asalariados en Uruguay, y $31.9 \%$ en Argentina, no estaban todavía registrados en la seguridad social (no importa si trabajando en la economía formal o informal), y por consiguiente se mantuvieron por fuera de estos acuerdos neocorporativos $^{4}$. De este modo, el neo-corporativismo segmentado es similar al tradicional neo-corporativismo europeo en que el gobierno orienta pactos salariales centralizados con los sindicatos hegemónicos como aliados. A diferencia de los arreglos neo-corporativistas en los países desarrollados, sin embargo, estas negociaciones no se aplican a todos los asalariados sino a una porción sustancial de los mismos. El intercambio político también varía. En Europa, especialmente tras la caída del sistema de Breton Woods en los tempranos 70‘s, los sindicatos intercambian moderación salarial por política social y empleo estable. En la era neo-corporativista de Argentina y Uruguay, los sindicatos esencialmente intercambian mejoras en sus ingresos reales por moderación en las demandas salariales generales y en los conflictos

4 Fuente: Instituto de Estadísticas Nacionales en Argentina (www.indec.gov.ar ) y Uruguay (www.indec.gov.ar). 


\section{Sebastián Etchemendy}

laborales. A pesar de la alianza general gobierno-sindicatos, el movimiento obrero como organización de clase se mantuvo generalmente separada del liderazgo político del FA y del PJ (ver Luna, 2017, p. 234 para Uruguay y Levitsky, 2003 para Argentina)-aunque en el caso de Uruguay, los líderes sindicales tienen más representación en los consejos de políticas sociales y en el partido. Además, en Argentina el intercambio político con los sindicatos incluyó recompensas organizacionales, tales como posiciones de liderazgo en las agencias que regulan el sistema de salud y el transporte, o subsidios a los sindicatos aliados como Camioneros-ausentes en el caso uruguayo.

En Argentina, una vez que las negociaciones colectivas comenzaron a ganar impulso después de 2005, el gobierno trató de establecer parámetros de incrementos salariales mediante negociaciones con sus sindicatos aliados más cercanos. En el gobierno de Néstor Kirchner (2003-2007) y en el primero de Cristina Kirchner (2007-2011), el principal aliado en el movimiento obrero fue el sindicato de camioneros liderado por el Secretario General de la CGT, Hugo Moyano. El acuerdo salarial alcanzado con un puñado de empleadores y sindicatos liderado por los camioneros, frecuentemente firmado en una ceremonia en la Casa Rosada, se convirtió en una guía para el resto de la economía. Cuando los camioneros y otros sindicatos de transporte rompieron con Cristina Kirchner a finales de 2011, el gobierno pasó a negociar el parámetro general de salarios con un puñado de sindicatos grandes que dominaban la CGT pro-gobierno (construcción, metalurgia, trabajadores del Estado y comercio). Al mismo tiempo el gobierno de los Kirchner cerró acuerdos para el salario mínimo con la confederación nacional CGT (hegemónica entre los trabajadores privados) y la CTA (mayormente empleados públicos) en el Consejo de Salario Mínimo, todos los años, en el período 2004-2015. Finalmente, en 2008, el nuevo consejo de salario mínimo nacional para maestros (Paritaria Nacional Docente) se convirtió en la base de la alianza con la principal Confederación Nacional de Maestros, CTERA, afiliada a la CTA.

En Uruguay, en marzo de 2005, el gobierno del FA emitió una serie de decretos que ordenaron la restauración de los Consejos de Salario. Se creó el Consejo Superior Tripartito (CTS) a nivel nacional, en el cual los representantes de los empleadores, la confederación nacional del trabajo PIT-CNT y las principales asociaciones de empleadores decidieron sobre los Consejos de Salario (formado por representantes del Estado, Federaciones sindicales y cámaras de negocios) que comenzarían a funcionar en cada sector. Para mediados de 2005, 20 grupos tripartitos que cubrían todo el sector privado estaban negociando los nuevos niveles salariales. El gobierno hizo una presentación formal de "pautas» para el incremento del salario en cada ronda de negociación (aproximadamente cada dos años) en el seno del CST. Este 
consejo también discutió y recomendó un salario mínimo para ser decretado por el Poder Ejecutivo. Finalmente, el FA también organizó una serie de Consejos de Salario Bipartitos (es decir estado/sindicatos) separados para los empleados públicos en la administración central, educación y empresas estatales $^{5}$.

\section{GRÁFICO 1}

Argentina y Uruguay: Incremento del Salario Real bajo Negociación Salarial Centralizada

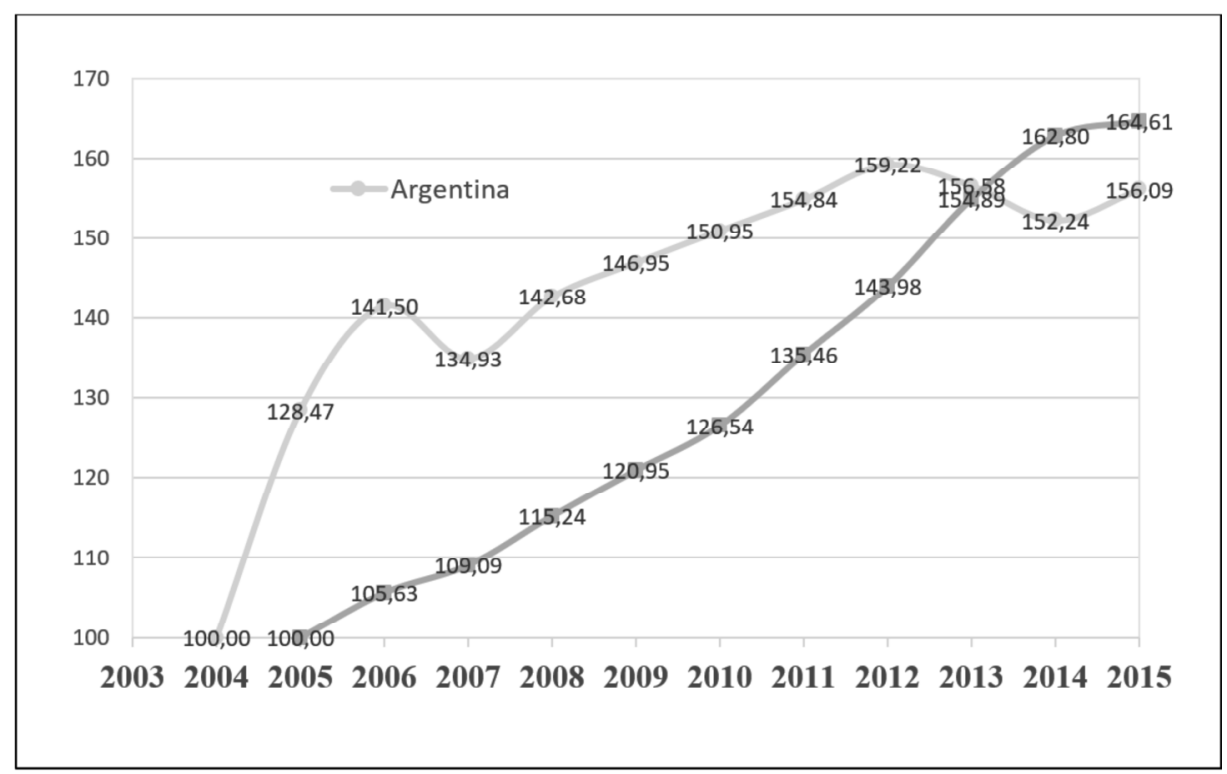

Fuente: Base de Datos de Contratos Laborales, ver Apéndice. Gráfico 2 y 3 excluyen a los maestros porque en Argentina, excepto por el salario mínimo, que comenzó a ser discutido en 2008, los salarios se establecen en negociaciones provinciales.

Ver Mazzuchi (2009) para una visión muy completa del lanzamiento de las negociaciones salariales centralizadas bajo el FA. 


\section{Sebastián Etchemendy}

El Gráfico 1 compara la evolución del salario real en los contratos colectivos de 22 sectores económicos (21 privados más la administración central del Estado), que están entre los más grandes en ambos países ${ }^{6}$. El salario que figura en los convenios es muy confiable para medir el poder de negociación sindical, en el sentido que no proviene de encuestas o datos administrativos generales, sino que refleja los números (ajustados por inflación) escritos en los contratos colectivos. En general, la política de ingresos tripartita en ambos países preparó el camino para un incremento fenomenal en los salarios reales de trabajadores cubiertos por el sindicato, alrededor del 55\%-65\% en diez años en ambos casos. Por supuesto este estudio no intenta sugerir que el neo-corporativismo es la única causa de este considerable crecimiento de los salarios reales; especialmente en tiempos de un boom de commodities, fuertes devaluaciones iniciales de la moneda, de alto crecimiento económico hasta 2010 — una explicación sistémica de los determinantes del crecimiento salarial en ambos países, está más allá del alcance de este estudio. Basta con decir que, para los gobiernos progresistas, los sindicatos y los trabajadores representados por ellos, el nuevo arreglo de la política salarial dio resultados por un largo tiempo. En Argentina el salario real creció sustancialmente hasta 2012, y se estancó después; en Uruguay el salario real creció continuamente en todo el período. El Gráfico 2 provee un indicador de neo-corporativismo y política de ingresos coordinada: el grado en el cual las negociaciones salariales en diferentes sectores son más o menos homogéneas, medidas como el desvío estándar del promedio en el crecimiento salarial en cada año. En Argentina parece claro que después de 2003-2005, cuando las negociaciones salariales coordinadas se consolidaron, la dispersión salarial cayó notablemente. En Uruguay no hay datos análogos disponibles para comparar salarios antes del gobierno del FA y de la política de ingresos coordinada, pero el gráfico sugiere que la dispersión salarial fue contenida.

6 Ver Apéndice. La Base de Datos de Convenios Laborales es la fuente de salarios en todos los gráficos. Cuando los salarios nominales son ajustados a la inflación, usé la inflación oficial en Uruguay tomada del Ministerio de Economía y Finanzas. En Argentina, usé la inflación oficial hasta 2007, cuando el Instituto Nacional De Estadística fue intervenido y los números dejaron de ser confiables. Por consiguiente, para 20072015, utilicé el índice de inflación del Instituto de los Trabajadores del Estados (ITE) basado en el promedio de cuatro provincias (CABA, Neuquén, San Luis y Tierra del Fuego) controlado por fuerzas de la oposición. 


\section{GRÁFICO 2}

Desigualdad Salarial: Desviación Estándar del Incremento Promedio del Salario Nominal por Año. Los 22 principales contratos sindicales

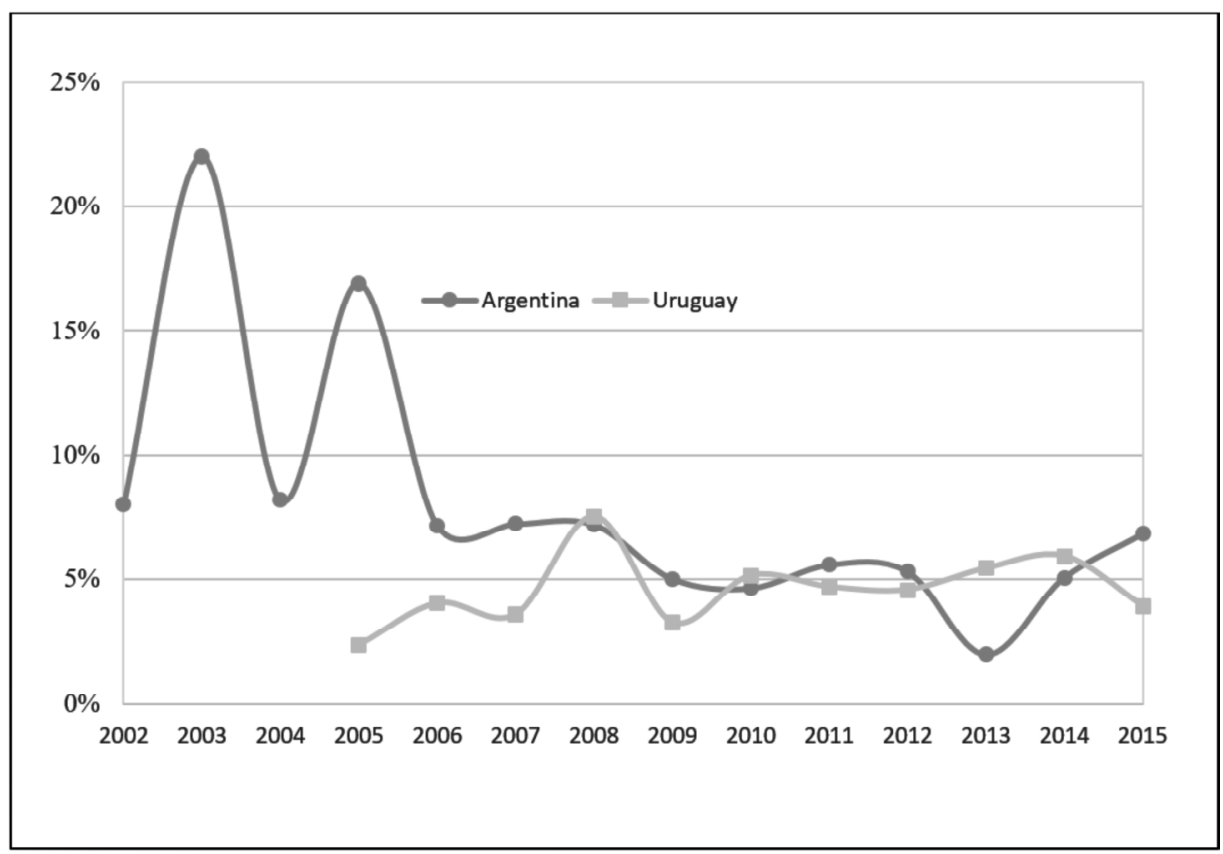

Fuente: Elaboración del Autor.

Este giro «en U» en las políticas de ingreso no significó, por supuesto, la ausencia de conflictos laborales o disputas entre el movimiento sindical y el gobierno. En este sentido, es importante enfatizar el carácter inequívocamente democrático del neo-corporativismo segmentado, una característica crucial para distinguir esta forma de representación de intereses y formulación de políticas del corporativismo estatal y del simple autoritarismo. Primero, en ambos países porciones o (en el caso de Uruguay) todo el movimiento obrero, emprendieron huelgas esporádicas pero importantes contra gobiernos aliados. Estas huelgas nacionales no fueron reprimidas o prohibidas por el Estado, tampoco lo fueron las huelgas sectoriales más comunes. Segundo, el Estado nunca rechazó ni declaró ilegal un acuerdo salarial. En Uruguay, bajo la ley 1943 el Estado podía rechazar un acuerdo salarial negándose a generalizarlo en forma de decreto-la reforma laboral del FA del 2009 en Uruguay descartó tal disposición y reguló que los contratos votados por los interlocutores sociales son automáticamente válidos. En Argen- 


\section{Sebastián Etchemendy}

tina el Estado debe «homologar» los acuerdos para hacerlos cumplir en todas las empresas de la actividad económica. Por supuesto, los gobiernos pudieron utilizar tales amenazas legales. No obstante, el Estado nunca revocó un contrato salarial, ni en el período de crecimiento económico y salarial hasta 2011, ni durante la recesión de 2012-2015. Finalmente, ningún sindicato individual, ni federación, ni confederación fue intervenido, hostigado o prohibido por el gobierno durante todo el período en ninguno de los dos países.

\section{c) Explicando la Emergencia del Neo-Corporativismo Sudamericano}

\section{1- El Legado de las Institucionales Laborales en Argentina y Uruguay}

¿Qué explica el auge de la coordinación salarial neo-corporativista en Argentina y Uruguay en los 2000? ¿Por qué fueron Argentina y Uruguay los únicos países que desarrollaron una política de ingresos tripartita con orientación nacional dentro de la ola de izquierda que barrió América Latina? La hipótesis 1 marca dos características institucionales concretas del siglo XX como un factor explicativo principal: la existencia de un marco legal «congelado» pero válido y aplicable para las negociaciones colectivas sectoriales/ nacionales cuando los gobiernos progresistas tomaron el poder, y el cuasi monopolio y carácter unificado del movimiento obrero en el nivel sectorial/ actividad económica. Estos legados institucionales fueron combinados por un tercer elemento clave en la teoría neo-corporativista: el rol jugado por el partido de base sindical tradicional (o del sector popular) ${ }^{7}$ en solucionar dilemas para la cooperación sindical y en reforzar el espacio de concertación salarial a través de reformas regulatorias.

A primera vista el desarrollo de la representación electoral/territorial y la política de intereses económicos en Argentina y Uruguay durante el siglo XX no podría ser más divergente (ver Collier y Collier, 1991). En Uruguay la incorporación de los sectores populares a la política fue canalizada por un partido de elite tradicional nacido en el siglo XIX (los Colorados en el período de Batllista entre 1903 y 1933). Solo en los tempranos 70' la izquierda agrupada en el FA construyó un partido de clase. Los sindicatos y la clase trabajadora fueron permeados por ideologías socialistas, comunistas, y anarquistas. Argentina, en contraste, es tal vez el caso arquetipo de incorporación obrera mediante un partido populista nuevo liderado por Perón en

En términos estrictos tanto el FA como el PJ dejaron de ser un partido de base sindical/ obrera con la fragmentación de los mercados de trabajo, y buscaron sujetos populares alternativos, ver Levitsky (2003) para Argentina y Luna (2014) para Uruguay. 
los tempranos 40'. A partir de esa época, los sindicatos peronistas marginaron los elementos de izquierda en el movimiento obrero. Se convirtieron en interlocutores políticos que representaban al peronismo ante los gobiernos durante las décadas de la postguerra, bajo regímenes autoritarios y democráticos por igual. En Uruguay, el movimiento obrero fue un actor político marginal hasta los 70', y enarboló una tradición fuerte de autonomía de clase frente al Estado ${ }^{8}$. Después de la dictadura sangrienta de los años 70, los sindicatos en Argentina continuaron afiliados al partido Peronista o Justicialista. En Uruguay el movimiento obrero fortaleció su alianza con el FA durante la transición democrática, y ambos permanecieron en oposición hasta 2005.

A pesar de las divergencias en las trayectorias, en Argentina y Uruguay, para la misma época (mediados de los años 40), la incorporación de la clase obrera en la política cristalizó marcos legales que promovieron la centralización de las negociaciones salariales colectivas sectoriales de alcance nacional. En Uruguay, el segundo Batllismo pasó en 1943 la Ley de Consejo de Salarios, que organizó negociaciones colectivas en grupos sectoriales a nivel nacional, monitoreados por el Estado. En Argentina, el peronismo estructuró negociaciones colectivas obligatorias a nivel sectorial. Más allá de diferencias en varios aspectos, en ambos casos estas regulaciones construyeron incentivos para organizar la representación de intereses a nivel nacional/industrial. Las negociaciones colectivas sectoriales sancionadas por el Estado favorecieron la unificación de la representación de actores en las negociaciones salariales ${ }^{9}$. Ambos marcos regulatorios para las negociaciones colectivas promovieron la inclusión obrera en economías semi-cerradas de la ISI hasta las reformas neoliberales de los años 90, especialmente bajo los gobiernos democráticos que las auspiciaron. En Uruguay los Consejos de Salario funcionaron entre 1944 y 1968, cuando fueron reemplazados por políticas de ingresos unilaterales y fueron luego restablecidas brevemente en los tardíos 80 (Mazzuchi, 2009, p. 17). En Argentina las negociaciones colectivas sectoriales tuvieron lugar mayormente en los interludios democráticos antes de 1976, y se reanudaron únicamente en 1988 en la última parte del gobierno de Alfonsín. En ninguno de estos casos, sin embargo, encontramos una política de ingresos tripartita centralizada y sostenida que estuviera orienta-

$8 \quad$ Lanzaro (1985, p. 55) refiere al movimiento obrero uruguayo entre el período de la postguerra y los tardíos 60 `s como «descentralizado y marcado por la compartimentalización y divisiones».

$9 \quad$ En Uruguay los Consejos de Salario tripartitos eran convocados legalmente por el Ejecutivo, pero el Estado no «garantiza ninguna atribución o reconocimiento legal. No hay cooptación laboral o códigos de exclusión»(Lanzaro, 1985, pp. 68, 49-51). En Argentina, en contraste, el Estado concede la representación monopólica a los sindicatos sectoriales más grandes. 


\section{Sebastián Etchemendy}

da por un partido pro-sindical, sin proscripciones a ningún actor económico organizado.

Significativamente, estos marcos legales no se desmantelaron y ni se remplazaron ni bajo los autoritarismos en los años 70' y 80', ni bajo los gobiernos neoliberales de los 90'. El neoliberalismo democrático en ambos países promovió de facto la flexibilización laboral y la negociación descentralizada como consecuencia de los ajustes de política monetaria y liberalización comercial. Pero no derogó la legislación laboral establecida ${ }^{10}$. Así, cuando los gobiernos pro-sindicales asumieron el cargo en 2003-2005, pudieron utilizar estos marcos legales «latentes» para «pagar» a su principal apoyo económico, los sindicatos, y aparecer como un aliado confiable.

Si la vieja legislación laboral aportaba el marco legal, la estructura del movimiento sindical proveía el segundo pilar esencial para el neo-corporativismo. En Uruguay, a pesar de la temprana implementación de las negociaciones salariales sectoriales, y debido en gran parte a su tradición sindical «autonomista», el sindicalismo a nivel intersectorial nacional se organizó débilmente. Recién en 1965-1966, en el contexto de la radicalización de clase a nivel continental, un paso fundamental fue la unificación del movimiento sindical en el CNT (Convenión Nacional de Trabajadores), que pronto se convertiría en la base de apoyo obrero del FA (Lanzaro, 1985). En 1980, los sindicalistas de nivel de base que confrontaron la dictadura bajo la etiqueta de PIT (Asamblea Inter- Sindical de Trabajadores) consolidaron el camino para la unidad cuando formaron PIT-CNT. Esta «nueva» confederación abarcó la vieja organización obrera y el activismo nuevo. En Argentina, en cambio, bajo el peronismo, la legislación laboral sancionó un solo sindicato por sector y dio marco legal a las confederaciones nacionales. La CTA (Central de Trabajadores Argentinos) nació de la CGT en los 90', pero la principal división es a nivel confederal. A nivel sectorial (excepto en el Estado donde el pluralismo es la norma) los sindicatos de la CGT son hegemónicos en el sector privado y la CTA en los sindicatos de maestros.

En resumen, Uruguay siguió un camino de negociación sectorial descentralizada hasta los tardíos 60', cuando la representación sindical unificada nacional se forjó lentamente «desde abajo». Argentina fue un caso de corporativismo estatal clásico, en el cual el monopolio sindical fue forjado «desde arriba» desde los años 40. Sin embargo, la consolidación democrática Argentina después de 1983 lentamente favoreció la autonomía sindical del control más directo del Estado. En Uruguay, el movimiento obrero unificado se combinó con la centralización de las relaciones laborales después de 2005. La Figura 1 representa estas trayectorias alternativas, y señala los

10 Para las políticas de esta flexibilización de facto en América Latina ver Murillo y Schrank (2005), y Etchemendy (2011). 
períodos generales en los cuales existió algún tipo de negociación salarial agregada. Desde puntos de partida diferentes, en los años 40 (aunque con una base común en la negociación sectorial sancionada por el Estado) ambos países convergieron al neo-corporativismo segmentado a mediados de los años 2000.

\section{FIGURA 1}

Trayectorias Alternativas al Neo- Corporativismo Segmentado

\begin{tabular}{lll} 
Argentina & & \multicolumn{1}{c}{ Uruguay } \\
\hline $\begin{array}{l}\text { Corporativismo } \\
\text { Estatal }\end{array}$ & $\begin{array}{l}\text { Neo corporativismo } \\
\text { Segmentado }\end{array}$ & $\begin{array}{l}\text { Negociación Sectorial } \\
\text { Descentralizada } \\
(1946-1957,1988-89)\end{array}$ \\
$(2005-2015)$ & $(1943-1968,1985-90)$
\end{tabular}

Fuente: Elaboración del Autor.

Por supuesto, los gobiernos de tipo nacional popular/izquierda fueron vitales para diseñar una política de ingresos centralizada en ambos casos. Decretos del Ejecutivo fueron clave para lanzar la primera ronda de negociaciones tanto en Argentina como en Uruguay. Además, los gobiernos reforzaron las regulaciones para respaldar al sindicalismo y prevenir la defección o free-riding de los empresarios en la negociación sectorial. Las reformas de las leyes laborales de 2004 (Argentina) y 2009 (Uruguay), votadas por la mayoría del gobierno en el Congreso, confirmaron el carácter obligatorio de las negociaciones salariales centralizadas para los actores sociales, la vigencia de los convenios colectivos hasta ser reemplazados por uno nuevo, la prohibición de contratos a nivel empresa por fuera de los acuerdos sectoriales, y la extensión del convenio colectivos a trabajadores no afiliados en cada actividad.

d) Neo-corporativismo en Argentina y Uruguay:

Evaluando la Coordinación Salarial

\section{1- Coordinación Salarial (I): Dispersión Intersectorial}

La teoría neo-corporativa postula que las actividades económicas protegidas de la competencia internacional no pueden divergir en exceso de sectores expuestos para lograr una política salarial eficiente. Los sectores prote- 


\section{Sebastián Etchemendy}

gidos, o no transables, suelen tener más capacidad para aumentar salarios, ya que la ausencia de competencia facilita el traslado de esos incrementos a precios. Así, los sectores expuestos al comercio internacional y las empresas exportadoras sufren en estos casos suba de costos y presión de sus sindicatos para igualar los niveles salariales de los sectores protegidos (Pontusson, 1992; Swenson, 1991). Todo ello afecta la productividad en el sector transable. De hecho, el dominio de sindicatos bien anclados en el sector exportador industrial dentro de las confederaciones nacionales tales como el LO sueco o el DGB alemana, siempre ha sido considerado uno de los fundamentos de la coordinación salarial en Europa. En particular, Garret y Way (2000) han argumentado que cuando los trabajadores del sector público son más fuertes que los privados en la negociación salarial, la política de ingresos neocorporativa se desmorona. Siguiendo a Garret y Way (pp. 285-7) utilizo el aumento del salario nominal para testear la divergencia intersectorial en ambos países. El Gráfico 3 muestra la ratio del incremento promedio del salario nominal anual en Argentina y Uruguay para los 21 sindicatos privados más grandes, comparado con los sindicatos públicos de la administración central del Estado. El Gráfico 4 replica el cálculo para los mismos sectores privados, comparados con los maestros del sector público ${ }^{11}$. En ambos países los empleados estatales y los maestros tienen sindicatos fuertes, militantes y los trabajadores gozan de más protección contra despidos y jefes que sus contrapartes en el sector privado.

Algunos académicos que trabajan Uruguay sostienen que la fuerza y el radicalismo de los sindicatos del sector público, y su influencia dentro del movimiento obrero, afectan las políticas públicas igualitarias e incluso crean una «puja distributiva» dentro del FA (Luna, 2014, p. 33; Doglio, Senatore and Yaffe, 2004). Sin embargo, los gráficos 3 y 4 sugieren que los sindicatos del sector público no son un problema para el neo-corporativismo en Argentina y Uruguay. En Uruguay, el porcentaje de aumento salarial promedio en el sector privado después de 2007 ha fluctuado entre el $50 \%$ y el $100 \%$ sobre los de los estatales, excepto por un año. En Argentina la fluctuación es más reducida, pero los aumentos salariales del sector privado son casi todos más altos. Asimismo, el porcentaje de aumento en los sindicatos privados fue siempre más alto que para los maestros en el sector público en ambos casos, pero particularmente en Uruguay excepto por $2015^{12}$. En re-

11 En Argentina el salario de los maestros está determinado a nivel provincial; sin embargo utilicé el incremento del salario promedio para las 24 provincias.

12 En vista de estos datos no es sorprendente que en 2015 los sindicatos de maestros organizaran una serie de paros contra el FA (ver Pérez y Piñero, 2016) y que su aumento salarial sobrepasara el del sector privado por primera vez. 
sumen, la militancia salarial en el sector público en ambos países parece estar contrarrestada por la incapacidad de los sindicatos estatales para obtener aumentos y por las limitaciones presupuestarias.

\section{GRÁFICO 3}

Ratio del promedio del incremento del salario nominal:

Privado vs. Estatal (Administración Central)*

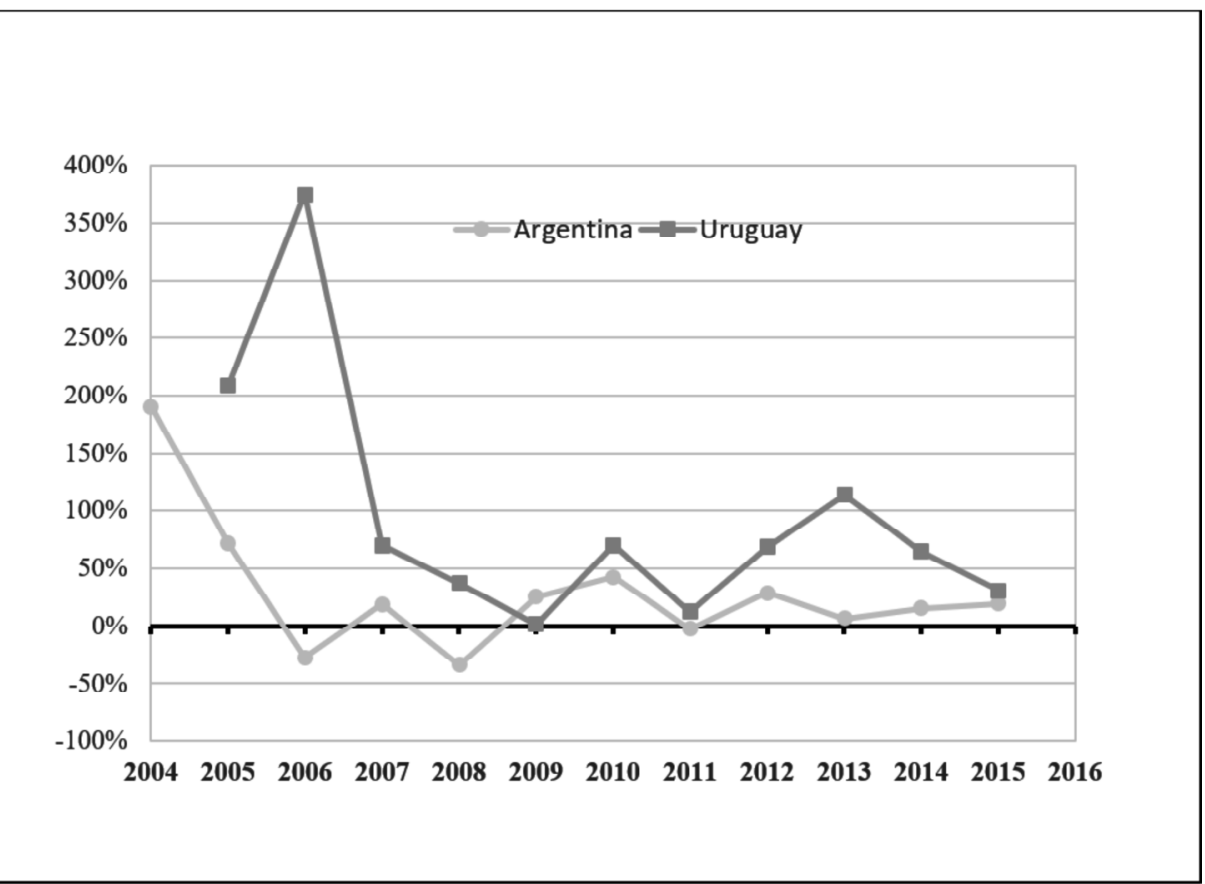

*Los números positivos indican mayor crecimiento en el sector privado.

Fuente: Elaboración del Autor. 


\section{GRÁFICO 4}

Ratio del promedio del incremento del salario nominal:

Privado vs. Estatal (Maestros)*

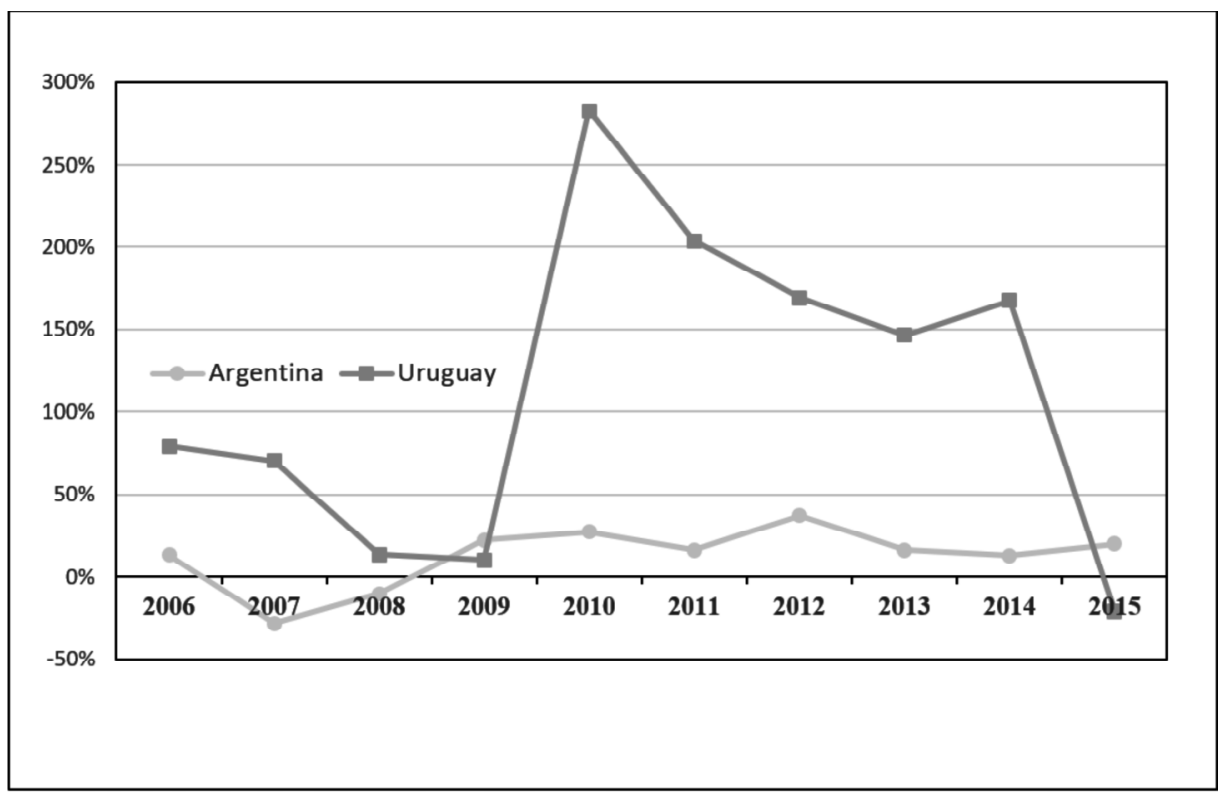

*Los números positivos indican mayor crecimiento en el sector privado.

Fuente: Elaboración del Autor.

El Gráfico 5 compara el desempeño salarial para sectores transables y no transables entre los 21 sindicatos más grandes de cada país ${ }^{13}$. En este caso la evidencia es más ambivalente para Uruguay. En ambos países el relanzamiento de una negociación salarial centralizada favoreció, en 20052008, a los sectores no transables (por ejemplo transporte), donde los sindicatos estuvieron posiblemente menos afectados por el período de liberalización previa. Seguidamente, en Argentina los sindicatos en el sector transable pudieron recuperarse y la brecha fue mínima; fluctuó alrededor del $10 \%$ positivo o negativo. En Uruguay, sin embargo, vemos una preminencia marcada de los sindicatos en el sector no transable, en donde los aumentos fueron entre el $10 \%$ y el $40 \%$ más alto, excepto por un año. Uno podría especular con que la debilidad comparativa del sector industrial en Uru-

13 Ver el Apéndice para identificar los sindicatos en los sectores públicos, transable y no transable. 
guay se manifestó en el pobre desempeño salarial de los sindicatos en el sector transable. La siguiente sección analiza si esta distorsión fue lo suficientemente fuerte para obstaculizar el gobierno de la política salarial por parte del FA.

\section{GRÁFICO 5}

Ratio del incremento promedio del Salario Nominal:

Sectores No comercializable vs. Comercializables.*

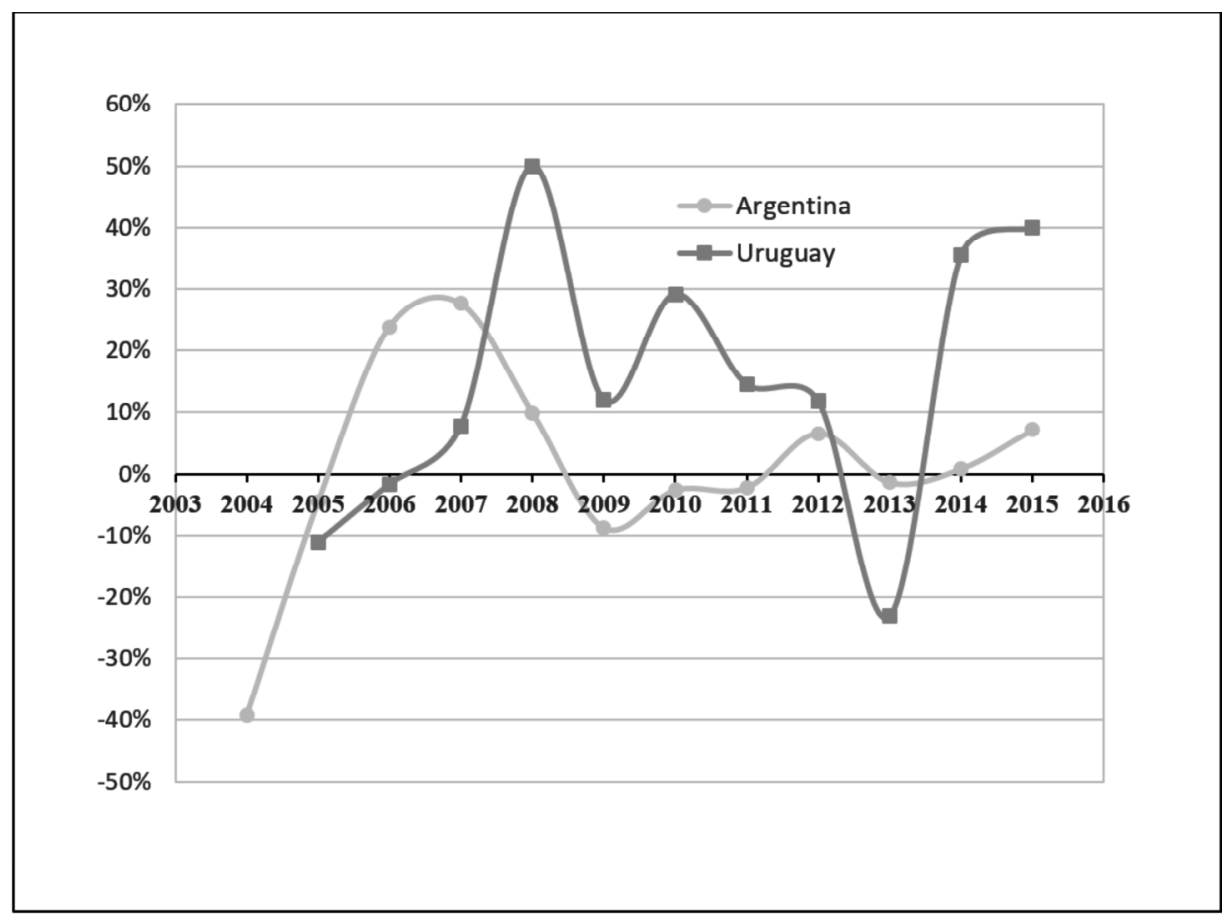

* Los números positivos indican mayor crecimiento en los No Comercializables.

Fuente: Elaboración del Autor.

2- Coordinación (II): Desempeño Salarial y Pautas Salariales del Gobierno

Una segunda medida de coordinación refiere a los parámetros de aumento que propone el gobierno en cada ronda de negociación. Tanto en Argentina como en Uruguay, el gobierno se esforzó por orientar los acuerdos salariales a sus metas de redistribución y manejo de la macro-economía. 
El kirchnerismo utilizó el pacto salarial con la fracción más cercana del movimiento obrero para (tratar de) anclar las expectativas de inflación. Con frecuencia los sindicatos aliados (hasta 2012 los camioneros en particular) tuvieron que defender el parámetro negociado con el gobierno de las críticas de sindicatos más combativos, contribuyendo, por lo tanto, a la moderación salarial. Por ejemplo, a inicios del 2008, con el alza de las expectativas de inflación, los sindicatos estaban demandando un ajuste del salario del $30 \%$, y las empresas sostenían que solo podían permitirse aumentar un $15 \%$. El gobierno se apuró a cerrar el acuerdo en febrero con un incremento del $19,5 \%$ (divido en tres cuotas durante el año) con el poderoso sindicato de camioneros liderado por el Secretario General de la CGT Hugo Moyano y los empleadores, con la esperanza de que sirviera como un parámetro para el resto de la economía ${ }^{14}$. En Uruguay el gobierno trató de usar sus pautas o «lineamientos» guía en las negociaciones colectivas para administrar las subidas del salario real. Por ejemplo, en la primera ronda de 2005, el gobierno propuso de 2 a $4 \%$ de incremento del salario real para los contratos del primer año, y 3,5 a 5\% para el siguiente período, iniciando en 2006. Para este fín, a la vez, recomendó ajustes de salario cada seis meses considerando la evolución de la inflación. Para la ronda del 2008/9 el gobierno proyectó un $2 \%$ de aumento real inicial o de «base», y periodos subsecuentes de ajuste a la inflación, pero abrió la posibilidad de un 1,5\% adicional de incremento del salario real en los sectores que podían afrentarlo.

¿Hasta qué punto se alcanzaron las metas de estos gobiernos en el mundo real? El Gráfico 6 describe la distancia entre las pautas de los gobiernos y el acuerdo salarial de cada año, para los 22 principales convenios colectivos firmados por los sindicatos (21 sindicatos en el sector privado más administración del Estado central). Dado que Argentina no implementó una política de ingresos de parámetros salariales formales, utilicé la distancia entre el parámetro nominal negociado por el gobierno con los grupos de sindicatos más cercanos desde 2006, y el promedio del aumento del salario nominal de cada año. Para Uruguay el gráfico mide el gap entre el máximo incremento del salario real recomendado por las pautas del gobierno en la ronda de cada año para cualquier sector, y el promedio verificado de incremento del salario real para los 21 convenios que tomamos cada año.

14 Moyano se reunió con los otros sindicatos grandes y trabajó para imponer el parámetro del gobierno. Ver Clarín y Página 12, 2/21/2008 


\section{GRÁFICO 6}

Gap entre los Parámetros de Gobierno/ Pautas y el Incremento Anual Real de Salario. Promedio de los Principales 22 Contratos Sindicales*

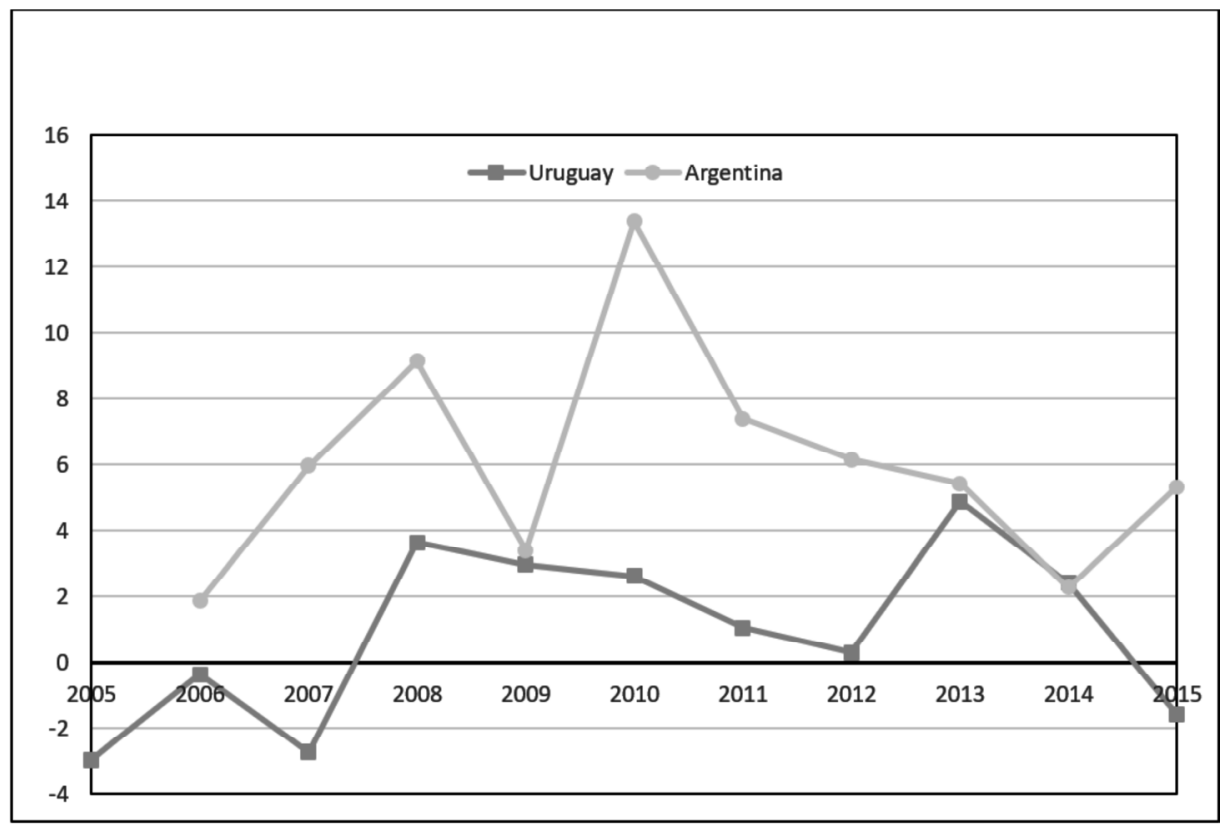

* Puntos porcentuales absolutos.

Fuente: Elaboración del Autor.

El Gráfico muestra que el gobierno de izquierda uruguayo fue más exitoso que su contraparte argentina en gobernar y coordinar las negociaciones salariales centralizadas. En Argentina la pauta negociada funcionó, en la práctica, como un «piso» de aumento salarial nominal. En promedio, los aumentos de salario nunca estuvieron por debajo del parámetro del gobierno. En buenos años económicos, tales como 2007, 2008 y 2010, los sindicatos (en un contexto de bajo desempleo y baja represión, apoyo gubernamental y crecimiento económico) empujaron los salarios nominales muy por arriba de las pautas de gobierno-algunas veces 9 e incluso 13 puntos porcentuales. El gráfico sugiere que, en los años no tan buenos, como 2009 (impacto de la crisis financiera mundial) y 2014 (crisis cambiaria), la presión del gobierno, combinada con la situación más apretada de las empresas, fue más capaz de contener el aumento del salario nominal. En términos reales, los salarios en Argentina crecieron hasta 2012 y luego se estabilizaron y declinaron levemente en 2013-15 (ver Gráfico 1). 


\section{Sebastián Etchemendy}

En Uruguay, en cambio, el crecimiento salarial estuvo mucho más cerca de las pautas del gobierno y, en algunos años, incluso debajo del ajuste máximo propuesto. El Gráfico 6 muestra que en los tres primeros años el gobierno logró con éxito coordinar la fijación de los salarios dentro de sus objetivos. En las rondas negociadas en 2008 (tercera desde 2005) y, especialmente, en 2012-13 bajo el presidente Mujica (quinta), hubo presiones más expansivas de los sindicatos (ver Carracedo y Senatore, 2016, pp. 26-7). Sin embargo, para 2015, comenzando la sexta ronda de negociaciones bajo el presidente Tabaré, el gobierno del FA incrementó los niveles de coordinación y logró controlar el crecimiento salarial bajo sus parámetros otra vez como en el período de 2005-2007.

\section{Explicando Grados de Coordinación: Política Monetaria y Centralización de la Negociación Salarial}

En un contexto similar de política salarial neo-corporativista por parte de los gobiernos de centroizquierda apoyados por los sindicatos, la comparación marca dos factores claves que determinaron una coordinación salarial más o menos efectiva: la política económica (especialmente monetaria), y el grado de centralización en la negociación salarial.

\section{a) Política Económica y Monetaria}

Como se señaló anteriormente, la literatura neo-corporativista de finales de los años 90 buscó integrar teorías sobre organización del mercado de trabajo con la economía post-keynesiana, en un mundo de movilidad de capitales. Una visión fundamental era que la política monetaria y la independencia del Banco Central no son una variable constante sino un factor clave que media los resultados de negociación salarial coordinada. De este modo, un juego de señales se abre: cuanto más centralizada es la negociación de salarios, los sindicatos tienen más incentivos para moderar a gremios individuales frente a un Banco Central «independiente» y una política monetaria restrictiva que puede producir desempleo. Del otro lado, un Banco Central independiente estará más inclinado a la disuasión monetaria cuando sea desafiado por sindicatos militantes no coordinados, que cuando se enfrenta a una negociación centralizada donde los sindicatos son capaces de moderar salarios (Franzese y Hall, 200, pp. 178-79; ver también Hall, 1994; Iversen, 1999).

Es apropiado leer la trayectoria del neo-corporativismo en Argentina y Uruguay, especialmente después del pico de crecimiento económico en 2010, 
y en la subsecuente caída del ciclo, a la luz de esta teoría sobre la interacción entre el Banco Central y las modalidades de negociación salarial. Argentina ejecutó una política monetaria expansiva desde 2003, con bajos niveles de independencia del Banco Central de la autoridad de la política económica. Después de la devaluación de 2002, un tipo de cambio depreciado dio margen de maniobra para tal expansión. Inicialmente, el Banco Central compró dólares disponibles en el mercado de cambios fruto de las exportaciones crecientes y recapturó esos pesos mediante bonos de medio término, con el objetivo de evitar el exceso de liquidez e inflación. A pesar de estos esfuerzos de esterilización, la oferta de dinero creció continuamente (Cetrángolo et. al., 2007). En efecto, el gobierno respondió a la crisis internacional del 2009 con un nuevo impulso de política monetaria expansiva y gasto fiscal. Enfrentándose a presiones crecientes sobre el tipo de cambio, el gobierno estableció control de capitales a fines de 2011. En 2012, la reforma de la carta del Banco Central incluyó los objetivos de empleo y crecimiento, y, más importante, incrementó el techo de transferencias al Tesoro Nacional. También estipuló que las mayores instituciones financieras guardaran una fracción de sus depósitos del sector privado en pesos para préstamos a la producción. Ambas medidas contribuyeron significativamente a la expansión monetaria a partir de entonces (ECLA 2013a p. 3). Mientras el PBI creció continuamente entre 2004 y 2010 (promedio 5,7), el desempeño fue mucho más errático después (en promedio 1,5 entre 2011 y 2015).

A diferencia de Argentina, Uruguay implementó una política monetaria de metas de inflación. Para 2005 el tipo de cambio inicialmente depreciado dio espacio para una expansión monetaria y estableció el escenario para las ganancias del salario real, en las rondas iniciales de negociaciones centralizadas. Sin embargo, el BCU (Banco Central Uruguayo) comenzó a establecer rangos explícitos de metas de inflación de 2005 en adelante, y utilizó las tasas interbancarias como principal instrumento. El gobierno maniobró la política monetaria para controlar la inflación y las presiones de apreciación del tipo de cambio en un contexto de fuerte entrada de capitales. En 2008 también reformó la carta del Banco Central. La reforma creó un Comité de Política Macroeconómica formado por tres representantes del Ministerio de Finanzas y tres del Banco Central, y estableció que el presidente de Uruguay tendría la palabra final en el caso de desacuerdos. Este comité establece las metas de inflación. Significativamente, la reforma sometió claramente la autoridad monetaria a los objetivos macroeconómicos del gobierno, y el presidente del Banco Central continuó siendo en la práctica designado por el Ministerio de Economía. Es decir, la reforma estuvo lejos de las concepciones neoclásicas. De hecho, en una de las bases de datos mundiales más citadas (Garriga, 2016) la independencia del Banco Central 


\section{Sebastián Etchemendy}

Uruguayo disminuyó bajo el FA. Sin embargo, al mismo tiempo, la nueva carta le dio amplio margen de maniobra al Banco Central para perseguir las metas de inflación con sus instrumentos elegidos, confirmó estabilidad monetaria como su principal tarea, y puso límites estrictos para financiar el tesoro. En otras palabras, consolidó los pre-requisitos institucionales para una política monetaria creíble orientada hacia las metas de inflación. Para 2013 el BCU pasó a utilizar la base monetaria en lugar de la tasa de interés para controlar la presión inflacionaria (ver ECLA 2013b). En el contexto de una tendencia regional de crecimiento, el PBI, con pico en 2010 (7,8\%), promedió $6,22 \%$ en $2005-2010$, y subsecuentemente cayó a un promedio de $3,39 \%$ en $2010-2015$.

En general, es claro que en un contexto de política de ingresos centralizada que empoderó a los sindicatos, es decir una que, dependiendo de los niveles de coordinación de salarial tripartita, puede ser propensa a empujar las expectativas de inflación, la política monetaria estaba orientada a contener esas presiones inflacionarias en Uruguay, pero no en Argentina. En el primer caso, tanto los instrumentos de política pública como la configuración institucional del Banco Central, se orientaron a construir una autoridad monetaria creíble que pudiera restringir las presiones desde el lado de la demanda. El Gráfico 7 muestra la evolución de la tasa de interés real (tasas nominales deflactadas) en Argentina y Uruguay 2005-2015. Argentina tiene tasas de interés negativas para todo el período, y especialmente desde 2010. En Uruguay, en contraste, después de 2007 (ver Lorenzo, 2010, p.159) y en 2011 el BCU levantó la tasa de política monetaria para evitar presiones inflacionarias. En efecto, 2011 marca el año pico en términos de incremento del salario nominal promedio en todo el período del FA (ver Gráfico 9 abajo), y es claro que la autoridad monetaria eligió un camino contractivo después de ese momento. La política monetaria no fue la única herramienta orientada a controlar la inflación. De hecho, el gobierno también recurrió a los controles y subsidios de los servicios públicos y a los acuerdos de precios y salarios en sectores particulares, especialmente bajo el gobierno de Mujica. El punto es, sin embargo, que su capacidad y la voluntad para controlar la inflación fueron mínimamente creíbles. 


\section{GRÁFICO 7}

Tasa de Interés real en Argentina y Uruguay, 2005-2015

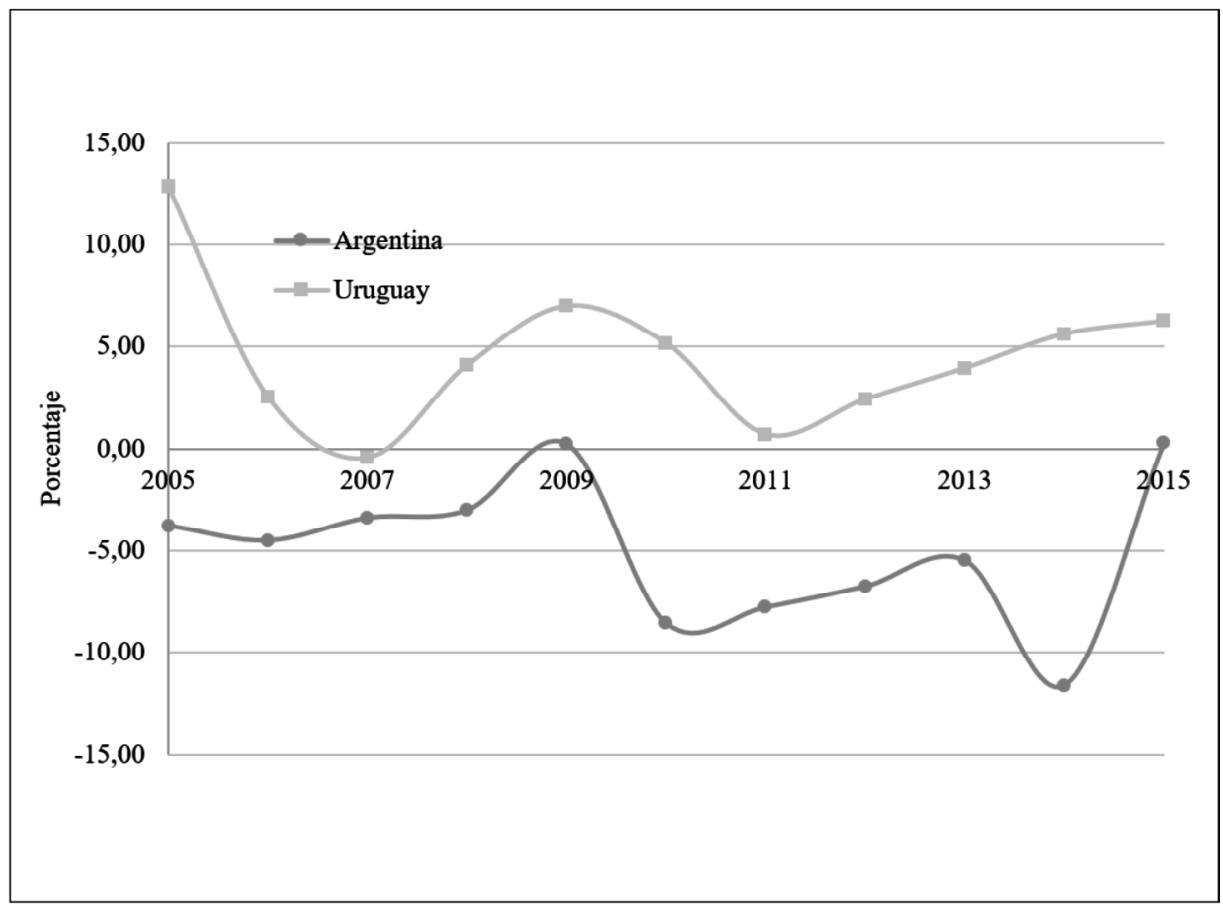

Fuente: FMI, International Financial Statistics, con datos del Banco Mundial sobre el deflactor del PBI.

La pregunta que surge es, ¿̇por qué una política monetaria ocasionalmente más restrictiva mejoró las perspectivas para la coordinación salarial del gobierno del FA en Uruguay? Sostengo que este es el caso por dos razones. Primero, la relativa credibilidad de las metas de inflación permite al gobierno anunciar a los actores económicos una pauta viable de salario para las negociaciones centralizadas. Ciertamente, uno de los problemas del gobierno en Argentina para coordinar un salario nominal en la ausencia de una proyección de inflación creíble, fue simplemente que cada actor estaba tentado a hacer «free-ride» y cubrirse a él mismo del riesgo de una inflación «desconocida». Segundo, y más importante, como Franzese y Hall (2000) e Iversen (1999) han discutido, una política monetaria de metas de inflación, si es mínimamente creíble, enviará señales más restrictivas a los actores económicos, especialmente los sindicatos. En efecto, un banco central formal- 


\section{Sebastián Etchemendy}

mente «independiente» puede servir a un gobierno de izquierda como un importante disuasivo en las negociaciones salariales, un hecho confirmado por mi trabajo de campo en y entrevistas en Uruguay. Un ex ministro de economía del FA declaró:

Fuimos a los sindicatos y les dijimos 'si esto no se arregla entre nosotros, el Banco Central lo va a arreglar. Y lo hará a su manera, hará un gran lío'. También les decíamos 'si no llegamos a un acuerdo racional, va a haber un actor que va a intervenir (es decir el Banco Central), y con una racionalidad muy diferente' ${ }^{\prime 15}$.

En Argentina tal «amenaza» de las autoridades del Ministerio de Economía, actuando como el «policía bueno» vis-à-vis del Banco Central (el policía malo), eran impensadas: cada actor sabía que el Banco Central estaba implementando una política monetaria expansiva impulsada por el gobierno. Los gráficos 8 y 9 muestran las expectativas de inflación del gobierno/Banco Central, la inflación real cada año y el incremento del salario nominal de cada año (eje izquierdo) contra el crecimiento del PBI (eje derecho) en ambos países. En Argentina, cuando el crecimiento económico se volvió más errático después del pico de 2010, tanto el salario nominal y la inflación se mantuvieron al alza, y la inflación generalmente dobló las expectativas del gobierno en el presupuesto. El desempleo, sin embargo, continuó disminuyendo debajo del $7 \%$ en $2015^{16}$. En Uruguay, un menor crecimiento del PBI fue acompañado por un declive en los salarios nominales, especialmente después de 2013 (Gráfico 9). De hecho, el año 2015 marca el nivel de crecimiento del salario nominal (y real) más bajo en Uruguay desde 2005. Como se mostró en el Gráfico 6 arriba, en la crucial ronda de 2015 el gobierno logró un aumento salarial por debajo del máximo «recomendado» en su propio lineamiento a los actores sociales-a pesar de conflictos y tensiones con el movimiento sindical (Pérez y Piñeiro, 2016, p. 356, ver también Bogliaccini y Queirolo, 2017, p. 595). Aunque la inflación continuó un punto o menos por encima de la meta del Banco Central, a diferencia de Argentina, la política salarial neo-corporativista del FA fue en gran medida capaz de moderar a los sindicatos aliados en tiempos de menor crecimiento económico. A pesar del ajuste monetario, en un contexto cercano a la recesión, los costos en términos de desempleo no fueron grandes ${ }^{17}$.

\footnotetext{
15 Entrevista del Autor con un alto funcionario del Ministerio de Economía del FA, Montevideo, Septiembre14, 2016.

16 Instituto Nacional de Estadísticas de Argentina (https://www.indec.gov.ar/).

17 El desempleo creció de 6,5\% en 2013 a 7,5\% en 2015 (http://www.ine.gub.uy/).
} 


\section{GRÁFICO 8}

Argentina (2004-2015): Aumento de salario nominal promedio, inflación esperada superior (presupuesto), inflación real y crecimiento del PBI

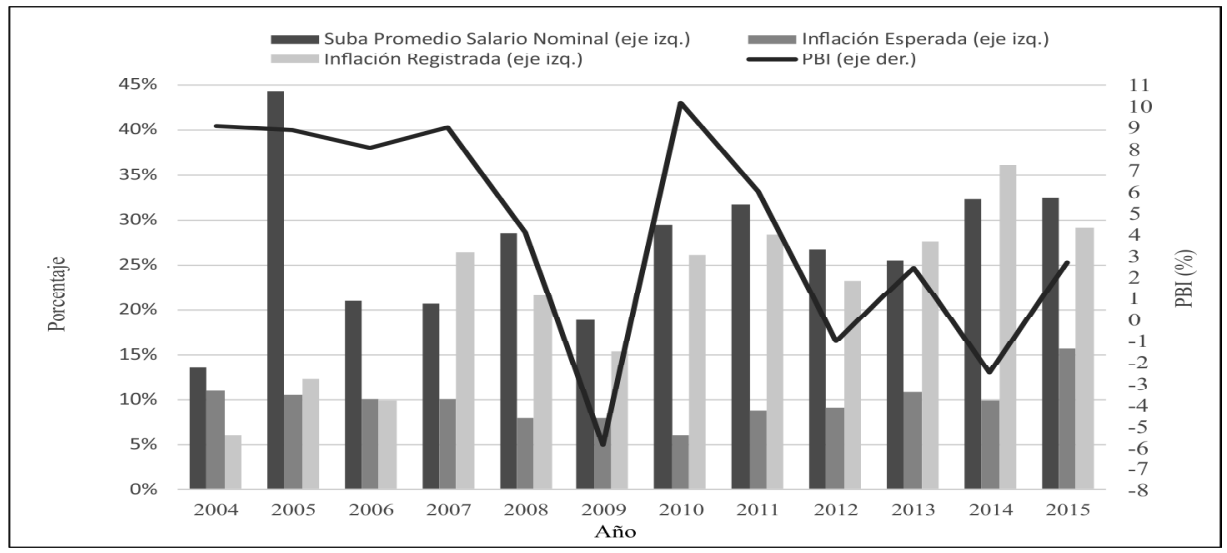

Fuentes: Promedio de los 21 contratos principales (Base de datos de contratos laborales). Proyecciones de inflación en Presupuesto enviadas al Congreso. Inflación: promedio de cuatro provincias, ver Apéndice. PIB, Banco Mundial.

\section{GRÁFICO 9}

Uruguay (2005-2015): aumento salarial nominal promedio, inflación máxima esperada (Banco Central), inflación real y crecimiento del PIB

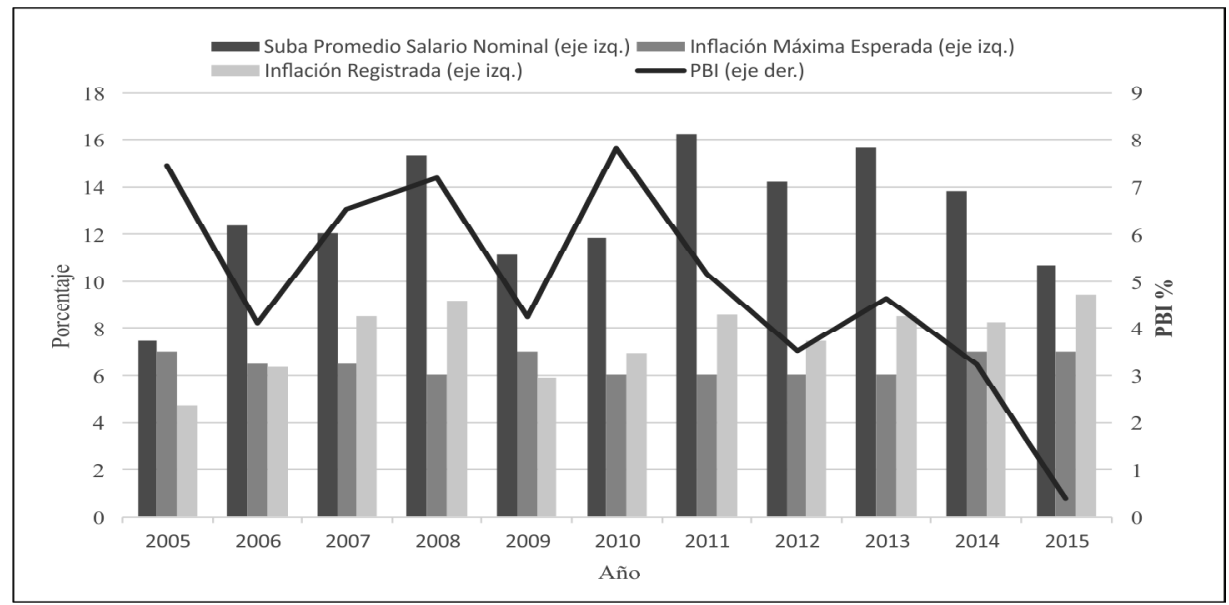

Fuentes: Salarios promedio de los 21 principales contratos sectoriales (Base de datos de contratos laborales, ver aplicación). Inflación esperada (máximo del rango objetivo, BCU). Inflación: Instituto Nacional de Estadística de Uruguay, crecimiento del PIB del Banco Mundial. 


\section{Sebastián Etchemendy}

\section{b)Centralización de la Negociación Salarial}

Argumenté, basado en la teoría neo-corporativista de la segunda parte de los años 90' que, en un mundo de movilidad de capitales, la política monetaria es una parte esencial del juego de señales en las negociaciones salariales agregadas. La configuración institucional del mercado de trabajo representa el otro lado de la ecuación para una coordinación efectiva. La literatura del neocorporativismo clásica postula que la centralización en las organizaciones sindicales, y en el proceso de formación salarial en general, contrarresta el free riding, es decir la no cooperación de los sindicatos individuales, y favorece la moderación salarial (Schmitter, 1981; Cameron, 1984). Si las autoridades económicas y laborales quieren gobernar la política salarial bajo el neocorporativismo, la eventual moderación de los sindicatos aliados es esencial. La mayor centralización de la negociación colectiva en Uruguay, argumento, mejora considerablemente la capacidad del gobierno para lograr la coordinación. Esta divergencia en el grado de centralización entre ambos países tiene tres fuentes definidas: el carácter formal de las pautas salariales, la existencia de un ámbito de negociación salarial de alto nivel (es decir suprasectorial), y la concentración de la confederación nacional de trabajadores.

Primero, y más importante, en Uruguay el gobierno presenta una guía formal de salarios para los actores sociales. Esta pauta es elaborada por el Ministerio de Economía y Finanzas (que, como se mencionó antes, proyecta las metas de inflación en conjunto con el Banco Central), en consulta con el Ministerio de Trabajo. En Argentina, cuando la negociación centralizada despegó después de 2004-5, los parámetros salariales para cada ronda fueron generados en una interacción informal centrada en el Ministerio de Trabajo. El Ministerio de Trabajo consultaba con el Ministerio de Economía y algunas veces con el presidente, sobre el parámetro conveniente. Al mismo tiempo, el ministro y su equipo obtendrían un sentido de las demandas sindicales y de las ofertas de los empresarios de un puñado de los sectores económicos más cercanos y políticamente aliados con el gobierno. De este modo, en ambos casos la negociación salarial finalmente evolucionó en torno a un parámetro influido por el gobierno. Sin embargo, el hecho de que en Uruguay el parámetro fuera explícito, y el gobierno implícitamente expresara que votaría su parámetro en caso de fuertes desacuerdos entre los actores sociales, sin duda ancló las negociaciones. En Argentina era más fácil para los actores económicos hacer free-riding, eludir parámetros que, en definitiva, nunca eran oficiales ${ }^{18}$.

18 Las figuras y las narrativas en esta sección se basan en entrevistas con el Ministro de Trabajo Carlos Tomada y la Vice-Ministro Noemi Rial, Buenos Aires Abril 2016, y su contraparte el ex ministro de Economía, Fernando Lorenzo, y al subsecretario de Trabajo, Nelson Loustaunau, en Uruguay, septiembre de 2016, y a otros actores clave involucrados en el proceso. 
Segundo, en Uruguay los lineamientos gubernamentales para cada ronda de salarios son presentados a los empresarios y las organizaciones de trabajadores en el Consejo Superior Tripartito (CST) creado por el FA (ver Figura 2). Una vez que son discutidos en el CST, son derivados a cada consejo sectorial, que las toma como parámetro en sus negociaciones. Si bien las recomendaciones salariales no se votan formalmente en el CST, en la práctica el consejo intermedia entre los objetivos macroeconómicos del gobierno y las condiciones económicas sectoriales en el terreno. La difusión de estos parámetros a los consejos sectoriales en los cuales los mismos actores que los discuten en el CST están representados, facilita considerablemente las negociaciones. En efecto, en Uruguay a diferencia de Argentina, el Estado manda a los representantes del Ministerio de Trabajo no solo la CST, y los consejos de salarios sectorial, sino también a muchos «subgrupos» que operan dentro de cada sector, algunos de ellos compuestos por actores que negocian en nombre de no más de varias docenas de trabajadores. Por lo tanto, en términos de las medición de centralización de la negociación neo-corporativa que establecen Wallerstein y Golden (2000: 112-3), Uruguay constituye un caso de «fijación central sin sanciones», solo debajo de «fijación salarial central con sanciones.»

\section{FIGURA 2}

El Proceso Organizacional de la Negociación Salarial Neo-Corporativista en Uruguay

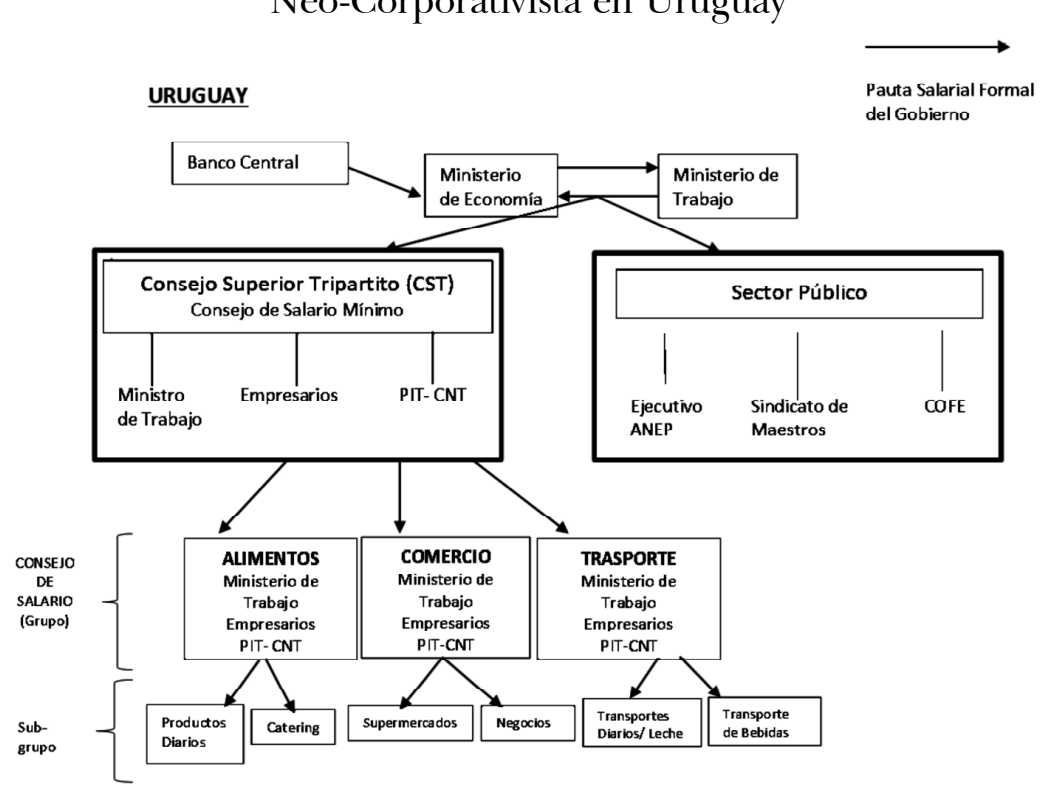

Fuente: Elaboración del autor. 


\section{Sebastián Etchemendy}

Argentina carece de un ámbito institucional formal e intersectorial para las negociaciones salariales (Figura 3). Es más, en Argentina solo las grandes negociaciones/sectores salariales tienen participación directa del Estado. La mayoría de los sectores funcionan con una base bipartita, con negociaciones autónomas entre los representantes sectoriales de sindicatos y empresarios, a menos que la paritaria se estanque y el Estado deba intervenir. En mesas separadas, el gobierno negocia con los actores sociales un salario mínimo para el sector privado y los trabajadores estatales, y otro para los maestros. La ausencia de cualquier instancia institucional formal de coordinación a nivel nacional agregada o intersectorial de salarios en Argentina facilita los acuerdos por actividad que van más allá de los parámetros del gobierno.

\section{FIGURA 3}

El Proceso Organizacional de las Negociaciones Salariales en Argentina

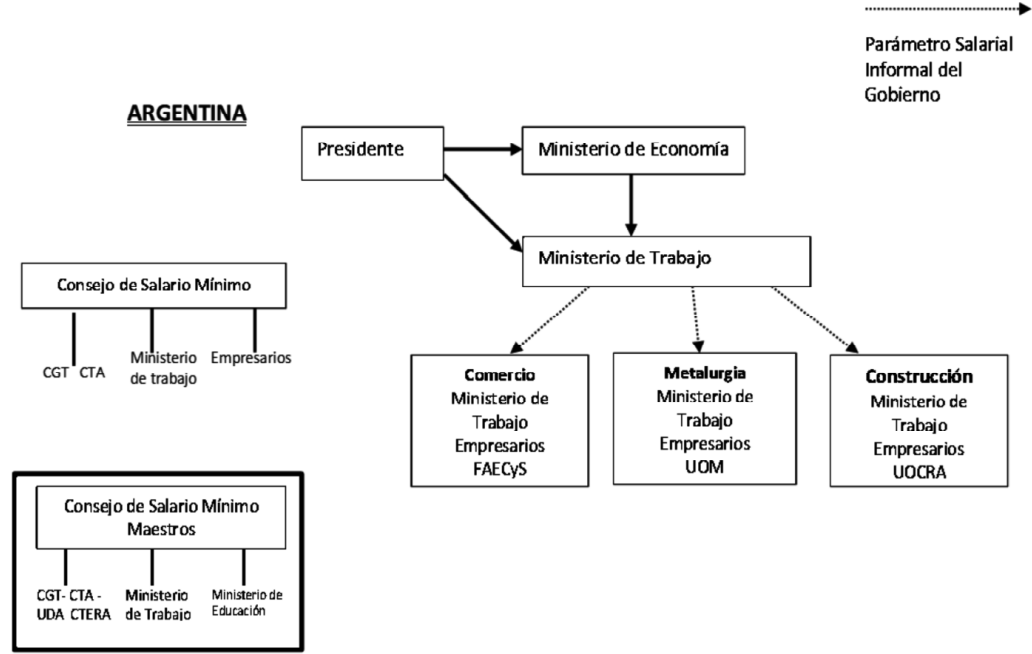

Fuente: Elaboración del autor.

Finalmente, un elemento clave en cualquier medición de la negociación salarial centralizada, es la concentración del movimiento obrero, es decir, el grado en el cual una sola confederación agrupa a la mayoría de los sindicatos (ver Golden, Wallerstein y Lange, 1999, pp. 205-7). Aunque en términos comparativos para la literatura institucional ambas naciones tienen un nivel alto de concentración inter-confederal, Uruguay aparece como 
un caso extremo, similar al de los países Nórdicos: sólo una confederación nivel nacional, PIT-CNT abarca todo el movimiento sindical. En Argentina dos confederaciones nacionales, la CGT y la CTA agrupan la gran mayoría de sindicatos sectoriales en el país-aunque casi todos los trabajadores privados están representados en la primera. Más importante, durante la mayor parte del período kirchnerista, la CGT estuvo de facto o informalmente dividida: hasta 2011 los sindicatos en los grandes sectores de servicios no siguieron el liderazgo de los sindicatos hegemónicos de transporte aliados con los Kirchner. Cuando Hugo Moyano, líder del sindicato de camioneros, rompió formalmente con el gobierno en 2012, se llevó con él la mayoría de los sindicatos de transporte y algunas organizaciones industriales menores, y la CGT se mantuvo dividida a nivel confederal hasta el final del período kirchnerista. La negociación de una pauta salarial formal más o menos uniforme con un liderazgo sindical dividido fue, especialmente después de 2011, problemática.

En suma, en Argentina las pautas salariales eran informales, no eran oficialmente discutidas en ningún ámbito institucional nacional o suprasectorial, y las divisiones sindicales a nivel confederal hicieron de la homogeneización o coordinación de las pautas salariales una tarea complicada. En Uruguay, en contraste, las pautas salariales elaboradas por el gobierno son explicitas y discutidas en un ámbito tripartito de alcance nacional, y con un único liderazgo del movimiento sindical. Irónicamente si uno considera la historia uruguaya de «autonomía» de los actores sociales del estado, el FA consolidó un proceso institucional de convenios colectivos que es sustancialmente más centralizado, vertical e intervencionista que en Argentina, modelo histórico de corporativismo estatal en el continente.

\section{Conclusiones: Dilemas de Institucionalización}

En este estudio intenté explicar el surgimiento y desempeño de las formas neo-corporativas de coordinación salarial en Argentina y Uruguay entre 2005 y 2015 . Utilicé una combinación de dos estrategias de método comparado tradicionales. Primero, el sistema de los casos más diferentes para distinguir las trayectorias comunes en Argentina y en Uruguay, a pesar de las divergencias históricas en sus desarrollos políticos. Rastrée la cristalización de marcos institucionales centralizados para la negociación colectiva (que sobrevivieron autoritarismos y neoliberalismos democráticos), y la consolidación de un movimiento sindical en gran medida unificado, afiliado a un partido de base popular, como prerrequisitos institucionales clave para el neo-corporativismo segmentado. Segundo, este estudio recurrió al sistema 


\section{Sebastián Etchemendy}

de los casos más similares para comparar los niveles de coordinación salarial. Subrayé como diferencias políticas e institucionales cruciales -una política monetaria más restrictiva y una mayor centralización de la negociación salarial- hicieron que la coordinación de la política de ingresos sea más efectiva en Uruguay que en Argentina.

¿Cuáles son las perspectivas de una mayor institucionalización del neocorporativismo en estas dos economías políticas sudamericanas? Este estudio subraya que el neo-corporativismo, como forma de política de ingresos centralizada y sostenida, puede existir en países periféricos incluso en una era de internacionalización económica. Sin embargo, el hecho de que sólo dos países latinoamericanos -Argentina, Uruguay- puedan ser catalogados como neo-corporativistas en los 2000 señala la dificultad para establecer formas de coordinación que eluden la primacía del mercado para discutir el ingreso en países en desarrollo. En efecto, el neo-corporativismo histórico en Europa Occidental se consolidó durante varias décadas, no en una sola, eventualmente evolucionando hacia los actuales modelos de capitalismo «coordinado». En su trabajo clásico Katzenstein (1985, p. 32) postula tres razones generales detrás de los arreglos democráticos-corporativistas permanentes: una ideología de colaboración social, grupos de interés concentrados y un sistema de partidos consensual.

En términos comparativos, Argentina y Uruguay pueden mostrar actores económicos relativamente unificados, especialmente a nivel sindical. Sin embargo, difícilmente se puede ver en estas naciones un consenso de diálogo social que trascienda partidos, tan crucial en los «pequeños» países nórdicos y países de Europa continental estudiados por Katzenstein. En Argentina, hacia 2018 el gobierno de centro-derecha de Macri, en el contexto de un enfoque de política monetaria fuertemente contractivo, ha evitado la coordinación salarial inter-sectorial con los sindicatos, y liquidado o diluido los consejos de salario mínimo para trabajadores privados y para los maestros. La continua polarización y el poder de la derecha en Argentina ha mutado el neo-corporativismo en acuerdos meramente sectoriales y descentralizados, y las relaciones gobierno-sindicatos se volvieron agrias. El neocorporativismo uruguayo también ha sido atacado por sectores de derecha y empresarios. Sin embargo, la reelección del FA de centro izquierda en 2014, junto con las características subrayadas en este artículo — principalmente la mayor capacidad para gobernar la fijación de salarios-implican mejores perspectivas para la institucionalización del neo-corporativismo en esta economía sudamericana. 


\section{Referencias bibliográficas}

Baccaro, L., y C. Howell (2011). A Common Neoliberal Trajectory: The Transformation of Industrial Relations in Advanced Capitalism. En Politics and Society, 39 (4), 521-563.

Bogliaccini, J., y R. Queirolo (2017). Uruguay 2016: mayorías parlamentarias en jaque y desafíos de revisión para sostener el modelo. En Revista de Ciencia Política, 37, 589-611.

Calmfors, L., y J. Driffill (1988). Bargaining Structure, Corporatism and Macroeconomic Performance. En Economic Policy, 3 (6), 13-61.

Cameron, D. (1984). Social Democracy, Corporatism, Labour Quiescence and the Representation of Economic Interest in Advanced Capitalist Society. En J. Goldthorpe (Ed.), Order and Conflict in Contemporary Capitalism. Oxford: Oxford University Press.

Carracedo, F., y L. Senatore (2016). Las políticas laborales y las relaciones de trabajo durante el gobierno de José Mujica. En Betancur N. y J. Busquets (Eds.), El Decenio Progresista. Montevideo: Fin de Siglo.

Centrángolo, O., D. Heymann, y A. Ramos (2007). Macroeconomía en recuperación: La Argentina post-crisis. En Kosacoff, B. (Ed.), Crisis, recuperación y nuevos dilemas: la economía argentina 2002-2007. Santiago: CEPAL.

Chasquetti, D. y D. Buquet (2005). Elecciones Uruguay 2004: descifrando el cambio. En Revista de Ciencia Política, 25, 143-152.

Collier, D. (1993). Trajectory of a Concept: 'Corporatism' in the Study of Latin American Politics. En P. Smith. (Ed.), Latin America in Comparative Perspective. Boulder: Westview Press.

Collier, R., y D. Collier (1991). Shaping the Political Arena. Princeton: Princeton University Press.

Collier, R. y D. Collier (1979). Inducements versus Constraints: Disaggregating 'Corporatism,'». En American Political Science Review, 73 (4), 967-86.

ECLA. (2013a). Economic Survey of Latin America and the Caribbean: Argentina.

ECLA. (2013b). Economic Survey of Latin America and the Caribbean: Uruguay.

Etchemendy, S. (2019). The Politics of Popular Coalitions. Unions and Territorial Social Movements in Post-Neoliberal Latin America (2000-2015). En Journal of Latin American Studies [en prensa].

Etchemendy, S. (2011). Models of Economic Liberalization. Cambridge: Cambridge University Press.

Etchemendy, S. y R. Collier (2007). Down but not Out: Union Resurgence and Segmented Neocorporatism in Argentina: 2003-2007. En Politics and Society, 35 (3), 363-401.

Franzese, R., y P. Hall (2000). Institutional Dimensions of Coordinating Wage Bargaining and Monetary Policy. En Iversen, T., J., Pontusson, y D. Soskice (Eds), Unions, Employers and Central Banks. Cambridge: Cambridge University Press. 


\section{Sebastián Etchemendy}

Garrett, G. y C. Way (2000). Public Sector Unions, Corporatism and Wage Determination. En Iversen, T., J. Pontusson y D. Soskice (Eds.), Unions, Employers and Central Banks. Cambridge: Cambridge University Press.

Garriga, A. (2016). Central Bank Independence in the World: a New Dataset. En International Interactions, 42 (5), 849-868.

Gerring, J. (2001). Social Science Methodology: a Criterial Framework. Cambridge: Cambridge University Press.

Golden, M., M. Wallerstein, y P. Lange (1999). Postwar Trade Union Organization and Industrial Relations in Twelve Countries. En Kitschelt, H, P. Lange, y G. Marks (Eds.), Continuity and Change in Contemporary Capitalism. Cambridge: Cambridge University Press.

Hall, P. (1994). Central Bank Independence and Coordinated Wage Bargaining: Their Interaction in Germany and Europe. En German Politics and Society, Fall, 1-23.

Hall, P. y D. Soskice (2001). Varieties of Capitalism. Oxford: Oxford University Press. Iversen, T. (1999). Contested Economic Institutions. Cambridge: Cambridge University Press. Iversen, Ty J. Pontusson (2000). Comparative Political Economy: a Northern European

Perspective. En Iversen, T., J. Pontusson y D. Soskice (Eds.), Unions, Employers and Central Banks. Cambridge: Cambridge University Press.

Katzenstein, P. (1985). Small States in World Markets. Ithaca: Cornell University Press. Lanzaro, J. (2011). Uruguay: a Social Democratic Government in Latin America. En

Levitsky, S. y K. Roberts (Eds.), The Resurgence of the Latin American Left. Baltimore: Johns Hopkins University Press.

Lanzaro, J. (1985). Sindicatos y Sistema Político. Montevideo: Fundación de Cultura Universitaria.

Levitsky, S. (2003). Transforming Labor-Based Parties in Latin America. Cambridge: Cambridge University Press.

Lehmbruch, G. (1977). Liberal Corporatism and Party Government. En Comparative Political Studies, 10, 91-122.

Lorenzo, F. (2010). La política económica del primer gobierno del Frente Amplio. En Bustos, P. (Ed.), Consenso Progresista. Buenos Aires: Fundación Ebert.

Luna, J. P. (2014). Segmented Representation. Political Strategies in Unequal Democracies. Oxford: Oxford University Press.

Luna, J. P. (2007). Frente Amplio and the Crafting of a Social Democratic Alternative in Uruguay. En Latin American Politics and Society, 49, 1-30.

Malloy, J. (Ed.). (1977). Auhtoriarianism and Coporatism in Latin America. Pittsburgh: University of Pittsburgh Press.

Mazzuchi, G. (2009). Las Relaciones Laborales en Uruguay de 2005 a 2008. En Working Paper 6. Geneva: ILO.

Murillo, V., y A. Schrank (2005). With a Little Help from my Friends. Partisan Politics, Transnational alliances and Labor Rights in Latin America. En Comparative Political Studies, 38 (8), 971-99. 
Pérez, V. y R. Piñeiro (2016). Uruguay 2015: los desafíos de gobernar por izquierda cuando la economía se contrae. En Revista de Ciencia Política, 36, 339-363.

Roberts, K. 2016. (Re) Politicizing Inequalities: Movements, Parties, and Social Citizenship in Chile. En Journal of Politics in Latin America, 8, 125-154.

Rossi, F. and E. Silva (2018). Introduction: Reshaping the Political Arena in Latin America. En Silva, E. and F. Rossi (Eds.), Reshaping the Political Arena in Latin America. Pittsburgh: University of Pittsburgh Press.

Scharpf, F. (1991). Crisis and Choice in European Social Democracy. Ithaca: Cornell University Press.

Schipani, A. (2018). Whither the Working Class? The Left and Labor Incorporation under Neoliberalism. [Paper presentado en la reunión anual REPAL, Bogotá, Colombia.]

Schmitter, P. (1981). Interest Intermediation and Regime Governability in Contemporary Western Europe and North America. En Berger, S. (Ed.), Organizing Interests in Western Europe. Cambridge, UK: Cambridge University Press.

Schneider, B. (2013). Hierarchical Market Capitalism in Latin America. Cambridge: Cambridge University Press.

Skocpol, T., y M. Sommers (1980). The Uses of Comparative History in Macrosocial Inquiry. En Comparative Studies in Society and History, 22, 174-197.

Soskice, D., y T. Iversen (2000). The Non-Neutrality of Monetary Policy with Large Price and Wage Setters. En Quarterly Journal of Economics, [Febrero], 265-284.

Streeck, W. (2006). The Study of Organized Interests: Before 'The Century' and After. En Crouch, C. y W. Streeck (Eds). The Diversity of Democracy. Cheltenham: Edward Elgar.

Swenson, P. (1991). Labor and the Limits of the Welfare State. Comparative Politics, 23, 379-99.

Wallerstein, M. y M. Golden (2000). Postwar Wage Setting in the Nordic Countries. En Iversen, T., J. Pontusson y D. Soskice (Eds.), Unions, Employers and Central Banks. Cambridge: Cambridge University Press. 


\title{
Sebastián Etchemendy
}

\section{Palabras Clave}

Latin America — political economy — neo-corporatism — labor — wage coordination

\section{Keywords}

América Latina - economía política - neo-corporativismo - sindicatos — coordinación salarial

\begin{abstract}
Neo-corporatism is in retreat in most of the advanced world, and was not part of the policy recipe in the majority of countries that staged the left-turn in Latin America in the 2000s. However, this article shows that Argentina and Uruguay after 2005 constitute cases of Segmented Neo-Corporatism, defined as a new form of centralized and tripartite wage policy oriented by the State in the region, which covers a substantial portion (registered workers), though not all, wage earners. The article traces de origins of this form of interest politics in both countries, and tests empirically the degree of wage coordination in the two dimensions of a) inter-sectoral dispersion between unions that operate in tradable, and non-tradable activities, and in the public sector and b) government capacity to influence effectively wage parameters. The study argues that a non-accommodating monetary policy and higher bargaining centralization largely explain the capacity of the Uruguayan neocorporatism to govern wage setting compared to its Argentine counterpart.
\end{abstract}

\section{Apéndice: Base de Datos de Convenios Colectivos}

Construí una base de datos con la evolución de los salarios nominales en los contratos colectivos de 23 sectores económicos (21 sectores privados más la administración del Estado y maestros) en cada país. Estos son los sectores están entre los más grandes en ambos países en términos de número de trabajadores.

En Argentina utilicé la base de datos del nivel de salario de los 22 sectores y maestros reunidos por la Subsecretaria de Programación Técnica y Estudios Laborales, Ministerio de Trabajo. El criterio que el Ministerio utilizó es que estos son los «más grandes y más representativos» (es decir cubren diversos sectores de actividades en el país). Aunque el Ministerio de 
Trabajo no recopila datos de todos los sectores más grandes, estos convenios cubren alrededor del $70 \%$ de los trabajadores registrados. Para maestros utilizo el salario promedio de las 24 provincias.

En Uruguay repliqué los mismos sectores, que abarcan los 21 del Consejo de Salario que funcionan en el sector privado y dos consejos bipartitos para maestros y la administración central del Estado. En Uruguay el Ministerio de Trabajo compila todos los contratos negociados en el Consejo de Salario del sector privado, pero no sistematiza salarios. Además, cada Consejo de Salarios está dividido en sub-grupos. Por lo tanto, mi asistente de investigación y yo revisamos manualmente los convenios, y sistematizamos la evolución del salario nominal de los dos mayores subgrupos en cada Consejo de Salarios, en la categoría de trabajo más baja. Estos dos sub grupos representan en promedio el $80 \%$ de los trabajadores en cada Consejo de Salario/sector. El Ministerio de Trabajo en Uruguay no provee datos sobre acuerdos salarios de empleados públicos, así que tomamos los niveles de salario de los empleados de la administración central de las publicaciones oficiales del Poder Ejecutivo (Boletín Oficial) que publica los acuerdos salariales estatales. En el caso de los maestros utilicé el Anuario Estadístico 2015 de la Administración Nacional de Educación Pública (ANEP). En el caso de Uruguay, los grupos sistematizados elegidos cubren aproximadamente el $80 \%$ de todos los trabajadores registrados.

A continuación, se detallan los convenios / sectores sindicales compilados para cada país:

\begin{tabular}{|c|c|}
\hline \multicolumn{2}{|c|}{ Privados } \\
\hline Transables & No Transables \\
\hline Alimentos & Bancarios \\
\hline Metales & Camioneros \\
\hline Auto partes & Comercio \\
\hline Zapatos & Construcción \\
\hline Cuero & Mantenimiento edilicio \\
\hline Electrónicos & Entidades civiles y deportivas \\
\hline Industrial de la impresión & Seguridad \\
\hline Plásticos & Salud \\
\hline Químicos & Transporte de pasajeros \\
\hline Textiles & Hoteles y restaurantes \\
\hline-
\end{tabular}

\begin{tabular}{|c|}
\hline Públicos \\
\hline Maestros \\
\hline Estado Nacional \\
\hline
\end{tabular}

